\title{
Medición y análisis de la vulnerabilidad a la exclusión social en España (2004-2009)*
}

\author{
ÚRSULA FAURA MARTINEZ
}

Departamento Métodos Cuantitativos para la Economía, UNIVERSIDAD DE MURCIA, ESPAÑA.E-mail: faura@um.es

\section{MATILDE LAFUENTE LECHUGA}

Departamento Métodos Cuantitativos para la Economía, UNIVERSIDAD DE MURCIA, ESPAÑA.E-mail: mati@um.es

\section{ANTONIO LOSA CARMONA}

Departamento Economía Aplicada, UNIVERSIDAD DE MURCIA, ESPAÑA. E-mail: alosa@um.es

\section{RESUMEN}

Con los datos suministrados por la Encuesta de Condiciones de Vida para cada uno de los años del periodo 20042009, se realiza un estudio de la vulnerabilidad a la exclusión social de la población adulta residente en España. Utilizando las técnicas del análisis factorial se determinan los principales factores que generan la exclusión social en España en cada año y se identifica a los individuos vulnerables. A partir de ello y, mediante el análisis cluster, se obtiene el perfil de estos individuos en función de distintas variables. Además, se ha estimado el riesgo a la exclusión social para varios colectivos sociales, utilizando diferentes indicadores.

Palabras clave: Exclusión social, vulnerabilidad, análisis factorial, análisis cluster.

\section{Measurement and Analysis of the Vulnerability to the Social Exclusion in Spain (2005-2009)}

\begin{abstract}
With the information supplied by the Survey of Living Conditions for each of the years of the 2004-2009, we realize a study of vulnerability to social exclusion of the adult resident population in Spain. Using the techniques of factor analysis we identify key factors that generate social exclusion in Spain each year and we identify vulnerable individuals. With analysis cluster, we obtain the profile of these individuals based on different variables. In addition, the risk has been estimated to the social exclusion for several social groups, using different indicators
\end{abstract}

Keywords: Social Exclusion, Vulnerability, Factor Analysis, Cluster Analysis.

Clasificación JEL: D1, D31, I31

\footnotetext{
* Trabajo englobado en el Proyecto de Investigación Séneca no 12043/PPC/09: "Los mercados locales de empleo en la Región de Murcia de los colectivos en riesgo de exclusión".

Agradecemos las valiosas sugerencias aportadas por dos evaluadores anónimos que han enriquecido este trabajo.
}

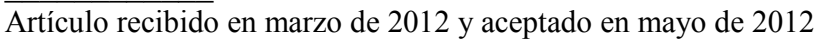

Artículo disponible en versión electrónica en la página www.revista-eea.net, ref. ə-30204 


\section{INTRODUCCION}

Los Consejos Europeos de Lisboa (marzo de 2000) y Feira (junio de 2000) proclamaron la integración social como eje estratégico fundamental de la Unión Europea en la primera década del presente siglo: "Convertirse en la economía basada en el conocimiento más competitiva y dinámica del mundo, capaz de crecer económicamente de manera sostenible, acompañada de una mejora cuantitativa y cualitativa del empleo y de una mayor cohesión social". Para el logro eficaz de ese objetivo estratégico, como ya reconociera el Consejo Económico y Social de Canarias (1998), las intervenciones no pueden limitarse exclusivamente a los colectivos en situación de exclusión social, sino que se precisa "intervenir en la zona de vulnerabilidad, a la que están llegando aquellos que habían estado perfectamente integrados en el orden del trabajo y el empleo seguros, personas y colectivos que seguirán engrosando, de forma irremediable, las bolsas de excluidos en nuestras ciudades si no se interviene a estos niveles. Es, en definitiva, poner en relación la pobreza severa, la marginalidad, con las zonas de vulnerabilidad en la que están inmersos cada vez más personas y colectivos, caracterizada por la precariedad en los empleos, fragilidad de las redes sociales..., y que, con cada vez mayor frecuencia, terminan en la exclusión social".

Pero, ¿qué se entiende por exclusión social?, ¿cómo se determina cuando un colectivo o un individuo tiene riesgo de exclusión social o es vulnerable a ella?

La Comisión Europea comienza a utilizar el término de exclusión social en el II Programa Europeo de la Lucha contra la Pobreza. No obstante, los orígenes del mismo se hallan en el ámbito de la política social francesa, René Lenoir, Secretario de Estado de Acción Social en el Gobierno de Chirac, en 1974 publica Les Exclus: Un Francais sur dix, y se refiere a un reducido conjunto de personas afectado por una lista de problemas de muy diversa naturaleza. Se alude a problemas de mala salud, asociados a situaciones de invalidez física o mental, o al envejecimiento de las personas. En otros casos, se trata de personas con una acusada propensión a conductas que ponen en riesgo su propia vida, como los suicidas o los consumidores de sustancias estupefacientes, o la vida de los demás, como los pederastas y otros delincuentes. Otros presentan una problemática múltiple, asociada a la monoparentalidad y la marginalidad. Los intentos de búsqueda de un perfil común se complican ante una problemática tan diversa, pero cabe destacar en todas esas situaciones la inadaptación, el desajuste personal y la marginalidad.

La abundante literatura posterior se empleó con eficacia en su empeño por incorporar a personas excluidas de la vivienda, el alimento, el ingreso, la cultura, la educación, la formación, los derechos, la dignidad, el respeto, la ciudadanía..., y de otras muchas esferas valiosas de la vida personal y social (Sen, Silver, De Haan). 
Probablemente este afán de expansión del ámbito subjetivo de la exclusión, junto a la multiplicidad de niveles en que se muestra la exclusión -el individuo, el hogar, la comunidad, la región o el país-, ha impedido una definición consensuada del término.

Siguiendo al Consejo Económico y Social de España, la exclusión social es tanto un estado como un proceso, que engloba las causas y los efectos de la pobreza, y que permite designar los procesos, situaciones y mecanismos en función de los cuales una parte de la población, personas, grupos o territorios, queda al margen de la participación en la vida social y económica (CES, 1996).

Otra definición de exclusión es la ofrecida por Subirats (2004): "El término exclusión social...alude a los crecientes procesos de vulnerabilidad, de desconexión social, de pérdida de lazos sociales y familiares que, junto con una combinación variable de causas de desigualdad y marginación, acaban generando situaciones...de imposibilidad o dificultad intensa para acceder a los mecanismos de desarrollo personal, de inserción sociocomunitaria y a los sistemas preestablecidos de protección social".

La noción de exclusión social surge cuando se quiere ampliar el concepto de pobreza y profundizar en su conocimiento analizando su carácter estructural y multidimensional. La descripción tradicional de la pobreza, basada en la privación material, no permite descubrir adecuadamente las causas de la diversidad de formas en que se manifiesta la privación humana. Junto a la privación material, basada en indicadores de ingreso y consumo, las situaciones que describen los pobres frecuentemente se refieren a privaciones en otros ámbitos, como educación y salud, vulnerabilidad y exposición al riesgo, o carencia de voz y de poder. La noción de vulnerabilidad recogida en el Informe de Desarrollo Mundial (Banco Mundial, 2000) alude al riesgo de que un hogar o individuo entre en situación de pobreza o tenga algún problema grave de salud a lo largo del tiempo. Asocia como vulnerabilidad la probabilidad de estar expuesto a una gran variedad de riesgos (violencia, crimen, desastres naturales, abandono escolar, etc.). En este sentido, la vulnerabilidad a la exclusión social denota además exposición al riesgo de exclusión, pero también comprende la capacidad de cada unidad de referencia (persona, hogar, comunidad, región, país) para enfrentarse a él, y adaptarse activamente en caso de su materialización efectiva.

La noción de vulnerabilidad no sólo da cuenta de los procesos históricos, sino que se interesa por la posibilidad de sufrir carencias en el futuro. La pobreza se entiende habitualmente como una situación real de carencia en diversos ámbitos claves de la vida de las personas, como los ingresos, los recursos, la capacidades; si bien, la vulnerabilidad une a la situación real de carencia la idea de que los entes vulnerables también tienen una mayor posibilidad de sufrir carencias sustantivas en el futuro; incorporando de esta manera la dinámica en el marco analítico. Así. Whelan y Maître (2005), definen como unidades vulne- 
rables a la exclusión social a aquellas cuyo riesgo sobrepasa un nivel socialmente crítico. En esta línea se sitúa, entre otros, el trabajo de Subirats et al (2004), en el que se estudia los desencadenantes del proceso de exclusión social en España a partir de la información suministrada por el Panel de Hogares de la Unión Europea (PHOGUE) en el año 2000.

A partir del año 2004, el PHOGUE fue sustituido por la Encuesta de Condiciones de Vida que incluye un módulo específico sobre exclusión social. Con la información suministrada por esta base de datos, para el periodo 2004-2009, se estudia este trabajo la vulnerabilidad a la exclusión social. Uno de los objetivos fundamentales del mismo es analizar los factores generadores de exclusión e identificar los colectivos que la padecen en mayor intensidad dentro del colectivo de adultos residentes en España.

Este trabajo está estructurado en varios epígrafes. Tras la introducción en la que se ha realizado un repaso del concepto de exclusión social y de vulnerabilidad, se presenta la base de datos con la que se trabaja y las variables utilizadas. En el siguiente apartado se obtienen los factores de vulnerabilidad a la exclusión social a través del análisis factorial, y su incidencia en distintos colectivos sociales se aborda en el cuarto. A continuación se define el perfil de estos individuos mediante el análisis de conglomerados, y se mide el riesgo de exclusión social. Se termina con las conclusiones más relevantes del estudio realizado.

\section{BASE DE DATOS Y VARIABLES UTILIZADAS}

\subsection{Base de datos}

El trabajo se ha realizado para el periodo 2004-2009 a partir de la información suministrada por la Encuesta de Condiciones de Vida (ECV) de cada año, cuyo objetivo general es "la producción sistemática de estadísticas comunitarias sobre la renta y las condiciones de vida, que incluyan datos transversales y longitudinales comparables y actualizados sobre la renta, el nivel y composición de la pobreza y la exclusión social, a escala nacional y europea"1.

Se trata de una encuesta, que incluye un módulo específico sobre exclusión social, dirigida a hogares privados, motivo por el cual no contempla a determinados colectivos susceptibles de graves problemas de exclusión como son las personas sin hogar y las que están alojadas en hogares colectivos (casas de acogida, pensiones, etc.) o instituciones (centros penitenciarios, residencias, asilos, etc.). Esta cuestión puede condicionar en parte los resultados obtenidos.

Los cuestionarios básicos de la ECV constan de los siguientes ficheros:

\footnotetext{
${ }^{1}$ Manual de la ECV varios años. INE.
} 
- Fichero de datos básicos del hogar. En él se encuentra información para identificar al hogar, localizarlo geográficamente, el grado de urbanización de la zona en que se encuentra y los factores de ponderación.

- Fichero de datos detallados del hogar. Tiene información exhaustiva sobre la vivienda, el equipamiento, la situación económica y los ingresos del hogar.

- Fichero de datos básicos de la persona. Es un fichero de personas en el que hay información sobre la nacionalidad y el estado civil.

- Fichero detallado de adultos ${ }^{2}$. Contiene un registro para cada persona adulta con las variables recogidas en el cuestionario individual. Informa de materias referidas a educación, salud, renta y trabajo.

Se ha trabajado con el fichero detallado de adultos al que se le ha ido agregando variables del resto de los ficheros a partir del identificador de la persona. Con esta base se ha analizado la estructura de la población adulta española atendiendo a distintas variables estructurales que, posteriormente, permitirán caracterizar a las personas susceptibles de vulnerabilidad a la exclusión social.

En la Tabla 1 aparece información relativa a la distribución de frecuencias de algunas características. La primera variable estudiada es el sexo. Se observa cómo la distribución de la población española durante el periodo 2004-2009, es muy similar, siendo siempre superior el porcentaje de mujeres frente al de hombres (esta diferencia es mayor en 2005).

Respecto al estado civil se observa como el porcentaje de personas solteras aumenta y el de casados disminuye si se compara el comienzo y el fin del ciclo, aunque hay distintas tendencias en los años intermedios. Los separados y viudos mantienen sus porcentajes y el número de divorciados se incrementa en un $72 \%$ en el periodo considerado.

En cuanto a la nacionalidad disminuye el porcentaje de la población española y comunitaria un 3,75\% frente a un incremento del $118,2 \%$ de los individuos del resto del mundo.

Independientemente del año estudiado, más del $50 \%$ de la población reside en zonas muy pobladas. La distribución del grado de urbanización se mantiene más o menos igual a lo largo del tiempo.

Lo más destacado respecto a los grupos de edad es el descenso cercano al $15 \%$ del porcentaje de jóvenes con una edad comprendida entre 16 y 29 años y un leve aumento de las personas entre 45 y 64 años.

\footnotetext{
${ }^{2}$ Se considera adulto a toda persona con 16 años o más.
} 
Tabla 1

Distribución de la población española según distintas variables

\begin{tabular}{|c|c|c|c|c|c|c|c|}
\hline & & 2004 & 2005 & 2006 & 2007 & 2008 & 2009 \\
\hline \multirow{2}{*}{ Sexo } & Hombre & 49,60 & 48,96 & 49,01 & 49,06 & 49,08 & 49,07 \\
\hline & Mujer & 50,40 & 51,04 & 50,99 & 50,94 & 50,92 & 50,93 \\
\hline \multirow{5}{*}{ Estado civil } & Soltero & 30,40 & 30,91 & 30,73 & 31,30 & 31,88 & 31,77 \\
\hline & Casado & 58,37 & 58,19 & 58,39 & 57,67 & 56,98 & 56,73 \\
\hline & Separado & 1,92 & 1,92 & 1,97 & 1,92 & 1,79 & 1,80 \\
\hline & Viudo & 7,89 & 7,69 & 7,64 & 7,41 & 7,34 & 7,36 \\
\hline & Divorciado & 1,35 & 1,26 & 1,20 & 1,68 & 1,97 & 2,32 \\
\hline \multirow{2}{*}{ Nacionalidad } & $\begin{array}{l}\text { España y Unión } \\
\text { Europea (UE) }\end{array}$ & 96,93 & 96,88 & 95,94 & 95,45 & 93,52 & 93,30 \\
\hline & Resto Mundo & 3,07 & 3,12 & 4,06 & 4,55 & 6,48 & 6,70 \\
\hline \multirow{3}{*}{$\begin{array}{c}\text { Grado de } \\
\text { urbanización }\end{array}$} & Muy poblada & 51,48 & 52,58 & 52,31 & 52,66 & 51,75 & 52,09 \\
\hline & Media & 20,65 & 20,02 & 20,02 & 19,96 & 21,01 & 20,90 \\
\hline & Poco poblada & 27,88 & 27,40 & 27,67 & 27,38 & 27,24 & 27,01 \\
\hline \multirow{4}{*}{ Grupos de edad } & $16-29$ & 21,47 & 20,72 & 20,10 & 19,78 & 19,21 & 18,31 \\
\hline & $30-44$ & 29,86 & 30,14 & 30,54 & 30,42 & 30,65 & 31,05 \\
\hline & $45-64$ & 27,76 & 28,34 & 29,00 & 29,32 & 29,56 & 29,99 \\
\hline & $>64$ & 20,91 & 20,80 & 20,36 & 20,48 & 20,58 & 20,66 \\
\hline \multirow{9}{*}{ Ocupación } & Grupo 1 & 3,97 & 3,78 & 3,77 & 3,79 & 3,90 & 4,15 \\
\hline & Grupo 2 & 7,86 & 7,44 & 7,74 & 8,33 & 8,74 & 9,09 \\
\hline & Grupo 3 & 8,06 & 7,15 & 6,80 & 7,33 & 8,08 & 8,03 \\
\hline & Grupo 4 & 7,66 & 8,56 & 9,31 & 9,65 & 9,88 & 9,81 \\
\hline & Grupo 5 & 13,05 & 12,61 & 12,86 & 13,05 & 14,03 & 13,48 \\
\hline & Grupo 6 & 3,77 & 4,67 & 4,07 & 3,66 & 3,50 & 3,80 \\
\hline & Grupo 7 & 15,33 & 14,65 & 13,93 & 14,28 & 14,35 & 14,23 \\
\hline & Grupo 8 & 7,91 & 6,04 & 5,64 & 6,15 & 6,12 & 6,41 \\
\hline & Grupo 9 & 16,51 & 16,85 & 16,68 & 17,00 & 16,87 & 16,70 \\
\hline \multirow{5}{*}{$\begin{array}{l}\text { Sector de } \\
\text { actividad }\end{array}$} & Asalariados & - & 39,47 & 43,05 & 42,34 & 43,38 & 39,78 \\
\hline & Empleadores $^{*}$ & - & 7,93 & 8,28 & 7,83 & 8,08 & 7,70 \\
\hline & Parados & - & 5,33 & 4,49 & 4,67 & 5,31 & 8,99 \\
\hline & Jubilados & - & 15,17 & 15,03 & 15,15 & 14,92 & 15,16 \\
\hline & Otra inactiv. & - & 31,92 & 28,89 & 29,85 & 28,20 & 28,10 \\
\hline
\end{tabular}

* Incluye también empresarios sin asalariados o trabajadores independientes.

Fuente: Elaboración propia a partir de la ECV en el periodo 2004-2009.

La variable ocupación ${ }^{3}$ recoge la "Clasificación Nacional de Ocupación" (CNO) que agrupa a los individuos ocupados en nueve grupos. Destacar que el

${ }^{3}$ La codificación de la CNO es la siguiente:

Grupo 1: Dirección empresas y de las Administraciones públicas

Grupo 2: Técnicos y profesionales científicos e intelectuales 
grupo 4, formado por los empleados de tipo administrativo, aumenta, en el periodo estudiado, un $28 \%$.

La variable que hace referencia al sector de actividad aparece en la ECV a partir de 2005. Se observa como el número de parados aumenta a partir de 2006, con una tasa de variación anual en el último año del $69,3 \%$. El porcentaje de asalariados se mantiene más o menos estable en el centro del periodo, registrándose una disminución de la tasa de variación en el último año del 8,3\%.

\subsection{Variables utilizadas en el estudio}

Las variables empleadas para construir los factores de vulnerabilidad se han agrupado en seis ámbitos distintos: económico, laboral, formativo, vivienda, ambiental y salud, cuya definición ${ }^{4}$ viene explicitada en la Tabla 2.

Todas ellas se han obtenido de los distintos módulos que se recogen en el fichero de datos detallados de personas: renta, exclusión social y vivienda; a excepción de la variable "pobre", que se ha construido siguiendo la metodología usual de identificación de la pobreza (se ha considerado pobre a aquella persona cuya renta equivalente está situada por debajo del $60 \%$ de la renta mediana equivalente de los hogares). Se ha de tener en cuenta que los datos sobre renta van referidos al año anterior y que, por tanto, difieren un año del resto de indicadores utilizados para calcular la vulnerabilidad.

Grupo 3: Técnicos y profesionales de apoyo

Grupo 4: Empleados de tipo administrativo

Grupo 5: Trabajadores de servicios de restauración, personales, de protección y vendedores de los comercios

Grupo 6: Trabajadores cualificados en la agricultura y en la pesca

Grupo 7: Artesanos y trabajadores de las industrias manufactureras, la construcción y la minería excepto los operadores de instalaciones y maquinaria

Grupo 8: Operadores y montadores de instalaciones y maquinaria fija y conductores y operadores de máquina móvil

Grupo 9: Trabajadores no cualificados

${ }^{4}$ Las variables están definidas de manera que muestran un sentido favorable a la vulnerabilidad. 


\section{Tabla 2}

Construcción de variables según distintos ámbitos

\begin{tabular}{|c|c|c|}
\hline \multirow{7}{*}{ 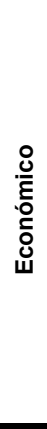 } & Pobre & $\begin{array}{l}\text { Personas cuya renta equivalente está por debajo del } 60 \% \text { de la renta } \\
\text { mediana equivalente de los hogares. }\end{array}$ \\
\hline & Pobreza subjetiva & $\begin{array}{l}\text { Personas que manifiestan tener mucha dificultad o dificultad para llegar a fin } \\
\text { de mes. }\end{array}$ \\
\hline & Necesidades alimentarias & $\begin{array}{l}\text { Personas que manifiestan no poder permitirse una comida de carne, pollo o } \\
\text { pescado al menos cada dos días. }\end{array}$ \\
\hline & Vacaciones & $\begin{array}{l}\text { Personas que manifiestan no poder permitirse ir de vacaciones fuera de } \\
\text { casa, al menos una vez al año. }\end{array}$ \\
\hline & Imprevistos & $\begin{array}{l}\text { Personas que manifiestan no tener capacidad para afrontar gastos } \\
\text { imprevistos. }\end{array}$ \\
\hline & Carga gastos vivienda & $\begin{array}{l}\text { Personas que manifiestan que los gastos totales de la vivienda suponen una } \\
\text { carga pesada. }\end{array}$ \\
\hline & Ayuda familiar & Personas que reciben la ayuda familiar del Estado. \\
\hline \multirow{6}{*}{$\begin{array}{l}\bar{\jmath} \\
\overline{0} \\
\overline{0}\end{array}$} & Contrato temporal & Personas con contrato laboral temporal de duración determinada. \\
\hline & Parado & Personas que manifiestan estar parados. \\
\hline & Inactivo reciente & Personas que han cambiado recientemente su actividad a inactivo. \\
\hline & Sin experiencia laboral & Personas que no han trabajado nunca. \\
\hline & Empleo bajo salario & Personas con salario inferior al Salario Mínimo Interprofesional. \\
\hline & $\begin{array}{l}\text { Trabajo doméstico y } \\
\text { familiar }\end{array}$ & $\begin{array}{l}\text { Personas cuya actividad principal son las labores del hogar y el cuidado de } \\
\text { niños u otras personas. }\end{array}$ \\
\hline \multirow{3}{*}{ 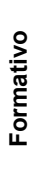 } & Estudios básicos & Personas que sólo han completado los estudios básicos. \\
\hline & $\begin{array}{l}\text { Estudios obligatorios } \\
\text { completos }\end{array}$ & Personas que han completado los estudios obligatorios. \\
\hline & $\begin{array}{l}\text { Sin estudios obligatorios } \\
\text { ni formación en cursos }\end{array}$ & $\begin{array}{l}\text { Personas con bajo nivel de instrucción que no cursan ningún tipo de } \\
\text { enseñanza compensatoria. }\end{array}$ \\
\hline \multirow{9}{*}{ 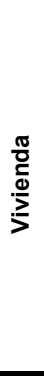 } & Teléfono & Personas que manifiestan no poder permitirse tener teléfono. \\
\hline & Televisor & Personas que manifiestan no poder permitirse tener televisor. \\
\hline & Ordenador & Personas que manifiestan no poder permitirse tener ordenador. \\
\hline & Lavadora & Personas que manifiestan no poder permitirse tener lavadora. \\
\hline & Coche & Personas que manifiestan no poder permitirse tener coche. \\
\hline & Luz natural & Personas que manifiestan tener escasez de luz natural. \\
\hline & Goteras & Personas que manifiestan tener problemas de goteras y humedades. \\
\hline & Baño & Personas que manifiestan no disponer de bañera o ducha. \\
\hline & Inodoro & Personas que manifiestan no tener inodoro con agua corriente. \\
\hline \multirow{3}{*}{ 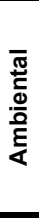 } & Ruidos & $\begin{array}{l}\text { Personas que manifiestan tener ruidos procedentes de vecinos o del exterior } \\
\text { de la vivienda. }\end{array}$ \\
\hline & Contaminación & $\begin{array}{l}\text { Personas que manifiestan que la vivienda tiene problemas de contaminación, } \\
\text { suciedad u otros problemas medioambientales producidos por la industria o } \\
\text { el tráfico. }\end{array}$ \\
\hline & Delincuencia & $\begin{array}{l}\text { Personas que manifiestan tener problemas de delincuencia o vandalismo en } \\
\text { la zona. }\end{array}$ \\
\hline \multirow{3}{*}{$\frac{\frac{\partial}{3}}{\infty}$} & Mala salud subjetiva & $\begin{array}{l}\text { Personas que manifiestan tener un estado general de salud malo o muy } \\
\text { malo. }\end{array}$ \\
\hline & Mala salud & Personas que tienen alguna enfermedad crónica o problemas de salud. \\
\hline & Discapacidad & $\begin{array}{l}\text { Personas que padecen una incapacidad que les impide intensamente o } \\
\text { hasta cierto punto el desarrollo de su vida diaria. }\end{array}$ \\
\hline
\end{tabular}

Fuente: Elaboración propia a partir de la ECV en el periodo 2004-2009. 
La incidencia de todas las variables analizadas se recoge en la Tabla 3. Se observa en el ámbito económico que, por regla general, todas las variables incluidas en el mismo sufren pequeñas variaciones anuales, salvo la variable "carga gastos vivienda" que aumenta anualmente con una tasa de variación en el periodo estudiado del $14,2 \%$. En 2009 , cerca del $31 \%$ de la población adulta manifiesta tener dificultades para llegar a fin de mes (pobreza subjetiva).

Tabla 3

Incidencia de las distintas variables según su ámbito

\begin{tabular}{|c|c|c|c|c|c|c|c|}
\hline & & 2004 & 2005 & 2006 & 2007 & 2008 & 2009 \\
\hline \multirow{7}{*}{ 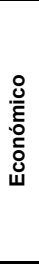 } & Pobre & 19,30 & 18,64 & 19,57 & 19,16 & 18,87 & 19,03 \\
\hline & Pobreza subjetiva & 28,10 & 25,98 & 28,97 & 26,63 & 29,27 & 30,83 \\
\hline & Necesidades alimentarias & 2,10 & 2,23 & 3,04 & 2,23 & 1,88 & 1,63 \\
\hline & Vacaciones & 43,97 & 40,92 & 39,80 & 36,33 & 34,10 & 39,52 \\
\hline & Imprevistos & 38,55 & 33,04 & 30,25 & 29,09 & 27,03 & 33,09 \\
\hline & Carga gastos vivienda & 44,85 & 45,68 & 47,11 & 48,18 & 50,70 & 51,22 \\
\hline & Ayuda familiar & 1,10 & 1,45 & 1,27 & 0,99 & 0,98 & 1,06 \\
\hline \multirow{7}{*}{ 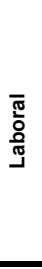 } & Contrato temporal & 9,39 & 9,85 & 9,99 & 9,67 & 9,40 & 9,44 \\
\hline & Parado & 8,36 & 7,15 & 6,60 & 6,14 & 6,90 & 11,36 \\
\hline & Inactivo reciente & 5,08 & 4,45 & 4,04 & 4,41 & 4,94 & 7,20 \\
\hline & Sin experiencia laboral & 14,86 & 16,96 & 19,38 & 16,15 & 13,81 & 13,46 \\
\hline & Empleo bajo salario & 13,52 & 15,04 & 14,64 & 15,44 & 15,27 & 13,52 \\
\hline & Trabajo doméstico y familiar & 13,57 & 15,69 & 14,20 & 12,35 & 12,05 & 13,57 \\
\hline & Trabajo a tiempo parcial & 5,25 & 5,01 & 5,16 & 5,29 & 5,23 & 5,24 \\
\hline \multirow{3}{*}{ 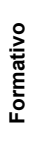 } & Estudios básicos & 31,36 & 37,72 & 38,03 & 33,32 & 31,85 & 30,21 \\
\hline & Estudios obligatorios completos & 58,74 & 57,51 & 60,47 & 55,82 & 54,81 & 54,65 \\
\hline & Sin estudios obligatorios ni formación en cursos & 55,18 & 54,50 & 56,87 & 52,85 & 51,66 & 51,49 \\
\hline \multirow{9}{*}{$\begin{array}{l}\frac{\pi}{0} \\
\stackrel{0}{0} \\
\stackrel{0}{>}\end{array}$} & Teléfono & 0,97 & 0,69 & 0,60 & 0,32 & 0,21 & 0,31 \\
\hline & Televisor & 0,23 & 0,17 & 0,12 & 0,13 & 0,07 & 0,08 \\
\hline & Ordenador & 13,19 & 10,27 & 9,58 & 7,50 & 6,76 & 6,18 \\
\hline & Lavadora & 0,31 & 0,28 & 0,33 & 0,21 & 0,18 & 0,26 \\
\hline & Coche & 5,95 & 5,26 & 4,07 & 4,07 & 4,53 & 4,39 \\
\hline & Luz natural & 13,17 & 10,30 & 10,93 & 10,56 & 5,71 & 6,84 \\
\hline & Goteras & 20,19 & 17,09 & 18,50 & 17,96 & 15,82 & 17,62 \\
\hline & Baño & 0,39 & 0,40 & 0,50 & 0,31 & 0,10 & 0,01 \\
\hline & Inodoro & 0,39 & 0,39 & 0,30 & 0,27 & 0,07 & 0,00 \\
\hline \multirow{3}{*}{ 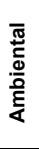 } & Ruidos & 24,78 & 28,87 & 26,02 & 25,96 & 21,99 & 22,97 \\
\hline & Contaminación & 15,47 & 16,68 & 15,97 & 16,32 & 13,45 & 14,03 \\
\hline & Delincuencia & 18,47 & 19,36 & 17,75 & 18,22 & 15,36 & 16,85 \\
\hline \multirow{3}{*}{$\frac{\overline{3}}{\frac{3}{\pi J}}$} & Mala salud subjetiva & 13,19 & 12,34 & 12,67 & 11,48 & 7,74 & 8,60 \\
\hline & Mala salud & 24,96 & 23,01 & 24,58 & 24,16 & 29,04 & 29,20 \\
\hline & Discapacidad & 22,98 & 21,73 & 23,24 & 22,51 & 22,06 & 23,86 \\
\hline
\end{tabular}

Fuente: Elaboración propia a partir de la ECV en el periodo 2004-2009. 
En el ámbito laboral, tras varios años de descenso, el número de parados empieza a aumentar a partir de 2007, y este aumento se agudiza en 2009. La misma situación se encuentra en la variable "inactivo reciente".

Todas las variables incluidas en el ámbito formativo tienen una incidencia mayor en 2006, a partir del cual sufren una disminución importante. Esta tendencia se da también en el ámbito de la vivienda, indicando que paulatinamente aumenta el número de hogares con ese equipamiento.

Las variables "ruidos", "contaminación” y "delincuencia” forman el ámbito ambiental. El comportamiento de las tres es el mismo, subidas y bajadas, aunque en el último año los porcentajes son menores que en el primero.

Por último, los individuos con alguna enfermedad o problema de salud crónica aumentan en un $17 \%$, mientras que la percepción subjetiva de enfermedad disminuye en un $34,8 \%$.

\section{OBTENCIÓN DE LOS FACTORES DE VULNERABILIDAD}

Uno de los objetivos de este trabajo es encontrar dentro del conjunto de adultos, aquéllos que presentan una mayor vulnerabilidad a la exclusión social. Para ello se ha utilizado la técnica estadística del análisis factorial cuyo objetivo es sintetizar la información compleja, proporcionada por un conjunto de variables, en unos pocos factores latentes. Se pretende resumir la información contenida en las variables originales, reemplazándolas por un número menor de nuevas variables, o factores, perdiendo con ese cambio el mínimo posible de la información contenida en las primeras. Estas nuevas variables gozan de la ventaja de estar incorrelacionadas entre sí y, además, pueden ordenarse de acuerdo con la información que llevan incorporadas. Como medida de la cantidad de información que recoge cada factor se utiliza su varianza, es decir, cuanto mayor es su variabilidad, mayor es su importancia informativa.

Para aplicar esta técnica se necesita calcular, en primer lugar, una matriz que recoja la variabilidad conjunta de todas las variables, para posteriormente extraer el número óptimo de factores. Con el fin de facilitar la interpretación de los mismos se procede a su rotación, de manera que las variables correlacionen fuertemente con alguno de los factores y escasamente con los demás. Para seleccionar el número de factores óptimo se ha seguido un criterio muy extendido, consistente en escoger aquéllos asociados a valores propios de la matriz mayores o iguales a la unidad. Por último, se estiman las puntuaciones de los individuos en las nuevas dimensiones. Estos factores son considerados factores de exclusión ya que proporcionan una aproximación métrica de la combinación de múltiples privaciones. 
Para aplicar el análisis factorial ${ }^{5}$, se requiere que se verifiquen unos requisitos mínimos como son el test de esfericidad de Bartlett y el valor del índice KMO (Kaiser-Meyer-Olkin) ${ }^{6}$. La muestra será tanto más adecuada cuanto más próxima esté a 1 esta medida, que sería una prueba de que los coeficientes de correlación parcial entre las variables originales son pequeños. Valores de KMO por debajo de 0,5 no suelen aceptarse, considerándose inadecuados los datos para aplicar un modelo de análisis factorial. A partir de los datos disponibles se ha obtenido, para todos los años, que el determinante de la matriz de correlaciones es muy pequeño, prácticamente cero, y tanto los valores de la prueba de esfericidad de Barlett como los del índice KMO (cercano éste a 0,7) indican que las variables originales son totalmente adecuadas para realizar un análisis factorial.

Una vez efectuado el análisis factorial sobre el conjunto de datos se han encontrado 11 factores para todos los años (excepto para 2006 y 2009 con 12) que explican alrededor del $60 \%{ }^{7}$ de la información contenida en la matriz original de datos.

A partir de la matriz de los componentes $\operatorname{rotados}^{8}$ se ha obtenido para cada individuo su puntuación factorial, la cual depende de las características de la persona, de forma que cuanto mayor sea su valor, más vulnerable es la persona en dicho factor'.

Para saber qué personas acaparan un número importante de factores de vulnerabilidad se calcula, para cada uno de los años, la suma ponderada de las puntuaciones factoriales del individuo $i, S_{i}$, según la ecuación:

$$
S_{i}=\sum_{j=1}^{n} \frac{w_{j}}{\sum_{j=1}^{n} w_{j}} P_{i j}
$$

siendo $P_{i j}$ la puntuación factorial del factor $j$ en el individuo $i, n$ el número de factores y $w_{j}$ el porcentaje de varianza explicada por el factor $j$ una vez rotado.

Esta variable es una medida de la acumulación de factores de vulnerabilidad en la persona y en la Figura 1 puede observarse, para cada uno de los años, que

\footnotetext{
${ }^{5}$ Para aplicar el análisis estadístico se ha utilizado el paquete informático SPSS.

${ }^{6}$ En Uriel (1995) y Pérez (2009) se puede profundizar sobre estos aspectos metodológicos.

${ }^{7}$ El porcentaje de la varianza explicada está en consonancia con los resultados obtenidos en otros trabajos sobre estos temas que aplican la técnica del análisis factorial, como en Subirats et al (2004), Poza (2008), Simo et al (2011).

${ }^{8}$ Se ha utilizado la rotación Varimax.

${ }^{9}$ Cada uno de los factores tiene media cero y los factores obtenidos presentan correlación positiva con las variables originales.
} 
su distribución es asimétrica, con una cola hacia la derecha, indicando que en cada uno de los años hay un pequeño grupo de personas en los que se dan un número elevado de factores de vulnerabilidad $\mathrm{y}$, por tanto, con mayor riesgo de exclusión social.

Los adultos vulnerables a la exclusión serán aquéllos que presenten un valor elevado en la variable suma ponderada, que por conveniencia se ha venido identificando en otros trabajos previos ${ }^{10}$ en el percentil 70 de esta variable (este percentil viene representado en la Figura 1 mediante una línea vertical gruesa). Se define, por tanto, como personas vulnerables a aquellas que componen el $30 \%$ superior de la distribución de la variable $S_{i}$.

Figura 1

Distribución de acumulación de factores de vulnerabilidad

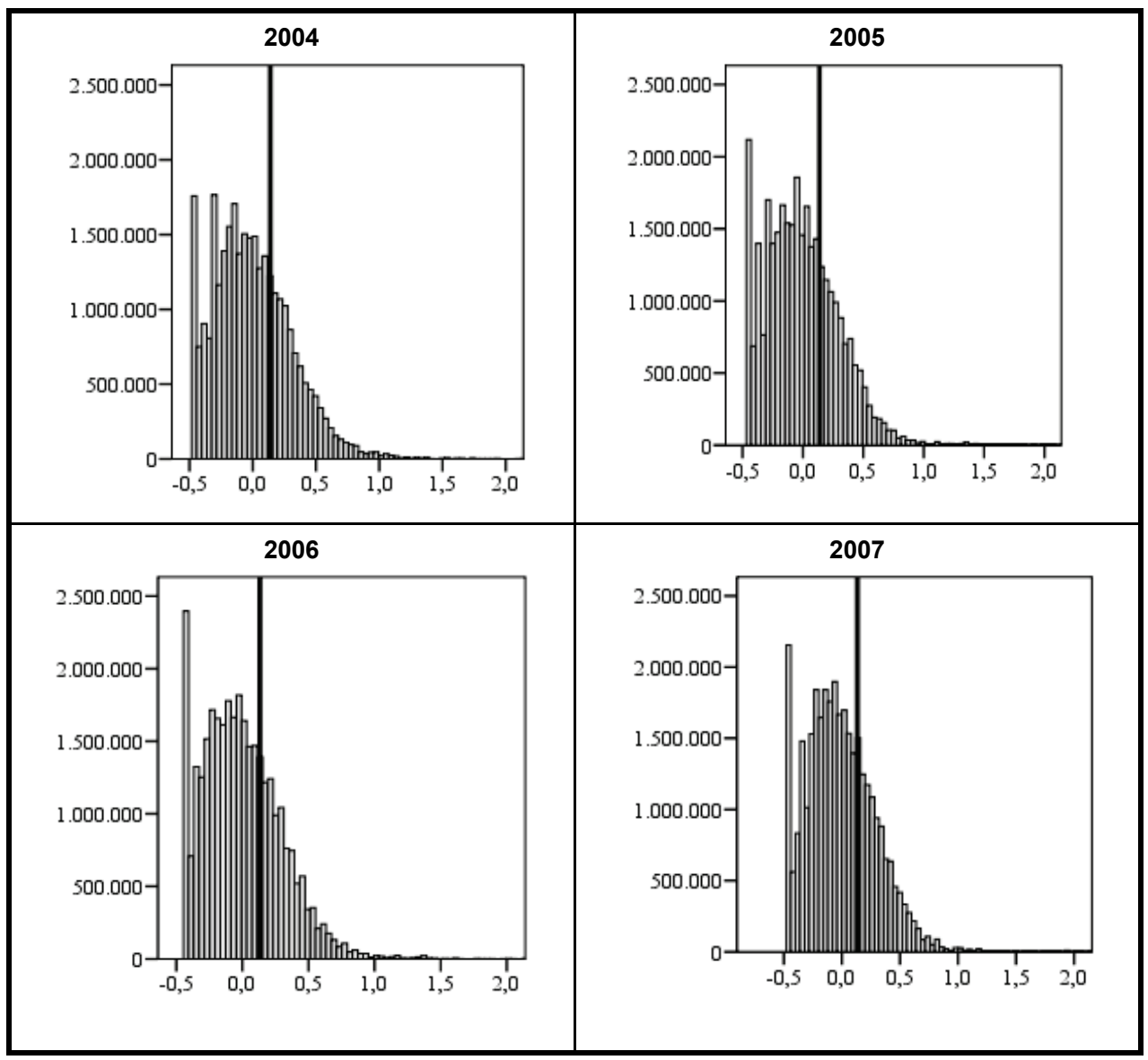

${ }^{10}$ Subirats (2004). 
Figura 1 (continuación)

Distribución de acumulación de factores de vulnerabilidad

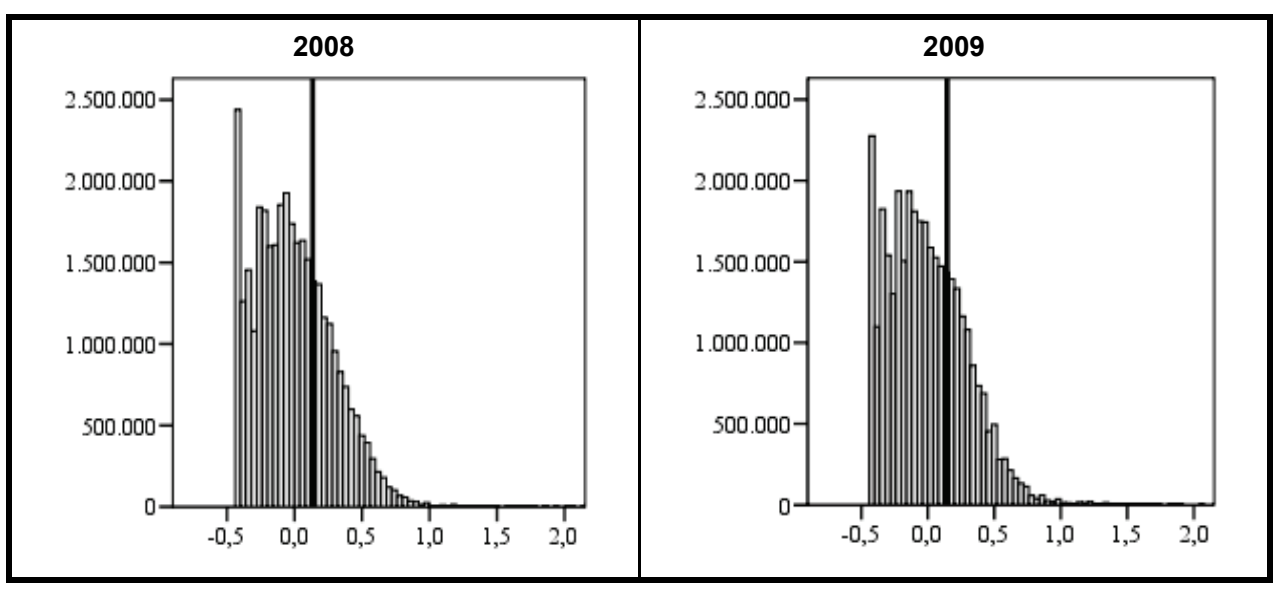

Fuente: Elaboración propia.

\section{INCIDENCIA DE LOS FACTORES DE VULNERABILIDAD}

Se ha identificado y etiquetado los factores de vulnerabilidad a la exclusión social (Tabla 4), teniendo en cuenta con qué variables están más correlacionados cada uno de los factores. En la tabla los factores están ordenados en función de la cantidad de información que explican.

Una vez identificados los factores, se estudia la incidencia que éstos tienen en los distintos grupos sociales definidos a partir de las variables estructurales, comparando el valor medio de cada factor para los distintos grupos. Así, los grupos sociales que presenten un nivel medio alto en algún factor indicarían que son muy vulnerables en dicho factor, mientras que los que tienen un valor negativo serían poco vulnerables.

Dado que en este trabajo se recoge información para el periodo 2004-2009, realizar un estudio exhaustivo para cada uno de los años puede resultar algo tedioso. Por ello, se analiza la evolución de los factores de exclusión sólo en 2005, 2007 y 2009 con la finalidad de estudiar los cambios temporales y determinar si ya empieza a ser perceptible en este periodo de tiempo el inicio de la crisis económica actual. 
Tabla 4

Identificación de los factores de exclusión

\begin{tabular}{|c|c|c|c|c|c|c|}
\hline & 2004 & 2005 & 2006 & 2007 & 2008 & 2009 \\
\hline F1 & $\begin{array}{l}\text { Percepción } \\
\text { subjetiva }\end{array}$ & $\begin{array}{c}\text { Nivel } \\
\text { formativo bajo }\end{array}$ & $\begin{array}{c}\text { Nivel } \\
\text { formativo bajo }\end{array}$ & $\begin{array}{c}\text { Nivel } \\
\text { formativo bajo }\end{array}$ & $\begin{array}{l}\text { Percepción } \\
\text { subjetiva }\end{array}$ & $\begin{array}{l}\text { Percepción } \\
\text { subjetiva }\end{array}$ \\
\hline F2 & $\begin{array}{c}\text { Nivel } \\
\text { formativo bajo }\end{array}$ & $\begin{array}{l}\text { Percepción } \\
\text { subjetiva }\end{array}$ & $\begin{array}{l}\text { Percepción } \\
\text { subjetiva }\end{array}$ & $\begin{array}{l}\text { Percepción } \\
\text { subjetiva }\end{array}$ & $\begin{array}{c}\text { Nivel } \\
\text { formativo bajo }\end{array}$ & $\begin{array}{c}\text { Nivel } \\
\text { formativo bajo }\end{array}$ \\
\hline F3 & $\begin{array}{l}\text { Enfermedad o } \\
\text { discapacidad }\end{array}$ & $\begin{array}{l}\text { Enfermedad o } \\
\text { discapacidad }\end{array}$ & $\begin{array}{l}\text { Enfermedad o } \\
\text { discapacidad }\end{array}$ & $\begin{array}{l}\text { Enfermedad o } \\
\text { discapacidad }\end{array}$ & $\begin{array}{l}\text { Enfermedad o } \\
\text { discapacidad }\end{array}$ & $\begin{array}{l}\text { Enfermedad o } \\
\text { discapacidad }\end{array}$ \\
\hline F4 & Desempleo & $\begin{array}{l}\text { Equipamiento } \\
\text { sanitario de la } \\
\text { vivienda }\end{array}$ & $\begin{array}{l}\text { Entorno de la } \\
\text { vivienda }\end{array}$ & $\begin{array}{c}\text { Equipamiento } \\
\text { sanitario de la } \\
\text { vivienda }\end{array}$ & $\begin{array}{c}\text { Equipamiento } \\
\text { sanitario de la } \\
\text { vivienda }\end{array}$ & Desempleo \\
\hline F5 & $\begin{array}{c}\text { Precariedad } \\
\text { laboral }\end{array}$ & $\begin{array}{l}\text { Entorno de la } \\
\text { vivienda }\end{array}$ & $\begin{array}{l}\text { Nivel laboral } \\
\text { bajo y pobre }\end{array}$ & $\begin{array}{c}\text { Entorno de la } \\
\text { vivienda }\end{array}$ & Desempleo & $\begin{array}{c}\text { Entorno de la } \\
\text { vivienda }\end{array}$ \\
\hline F6 & $\begin{array}{l}\text { Entorno de la } \\
\text { vivienda }\end{array}$ & Desempleo & Desempleo & Desempleo & $\begin{array}{l}\text { Entorno de la } \\
\text { vivienda }\end{array}$ & $\begin{array}{c}\text { Nivel laboral } \\
\text { bajo }\end{array}$ \\
\hline F7 & $\begin{array}{l}\text { Nivel laboral } \\
\text { bajo y pobre }\end{array}$ & $\begin{array}{c}\text { Nivel laboral } \\
\text { bajo }\end{array}$ & $\begin{array}{c}\text { Equipamiento } \\
\text { sanitario de la } \\
\text { vivienda }\end{array}$ & $\begin{array}{l}\text { Nivel laboral } \\
\text { bajo y pobre }\end{array}$ & $\begin{array}{l}\text { Necesidades } \\
\text { básicas }\end{array}$ & $\begin{array}{c}\text { Precariedad } \\
\text { laboral y } \\
\text { pobre }\end{array}$ \\
\hline F8 & $\begin{array}{l}\text { Necesidades } \\
\text { básicas }\end{array}$ & $\begin{array}{c}\text { Precariedad } \\
\text { laboral y } \\
\text { pobre }\end{array}$ & $\begin{array}{l}\text { Precariedad } \\
\text { laboral }\end{array}$ & $\begin{array}{c}\text { Precariedad } \\
\text { laboral }\end{array}$ & $\begin{array}{l}\text { Nivel laboral } \\
\text { bajo y pobre }\end{array}$ & $\begin{array}{l}\text { Necesidades } \\
\text { secundarias }\end{array}$ \\
\hline F9 & $\begin{array}{c}\text { Equipamiento } \\
\text { sanitario de la } \\
\text { vivienda }\end{array}$ & $\begin{array}{l}\text { Necesidades } \\
\text { Básicas }\end{array}$ & $\begin{array}{l}\text { Necesidades } \\
\text { secundarias }\end{array}$ & $\begin{array}{l}\text { Necesidades } \\
\text { básicas }\end{array}$ & $\begin{array}{l}\text { Precariedad } \\
\text { laboral }\end{array}$ & $\begin{array}{l}\text { Equipamiento } \\
\text { básico }\end{array}$ \\
\hline F10 & $\begin{array}{c}\text { Condiciones } \\
\text { físicas de la } \\
\text { vivienda }\end{array}$ & $\begin{array}{c}\text { Condiciones } \\
\text { físicas de la } \\
\text { vivienda }\end{array}$ & $\begin{array}{c}\text { Condiciones } \\
\text { físicas de la } \\
\text { vivienda }\end{array}$ & $\begin{array}{l}\text { Necesidades } \\
\text { secundarias }\end{array}$ & $\begin{array}{l}\text { Necesidades } \\
\text { secundarias }\end{array}$ & $\begin{array}{c}\text { Condiciones } \\
\text { físicas de la } \\
\text { vivienda }\end{array}$ \\
\hline F11 & $\begin{array}{l}\text { Precariedad } \\
\text { económica }\end{array}$ & $\begin{array}{l}\text { Precariedad } \\
\text { económica }\end{array}$ & $\begin{array}{l}\text { Necesidades } \\
\text { básicas }\end{array}$ & $\begin{array}{c}\text { Precariedad } \\
\text { económica }\end{array}$ & $\begin{array}{l}\text { Precariedad } \\
\text { económica }\end{array}$ & $\begin{array}{c}\text { Necesidades } \\
\text { Básicas }\end{array}$ \\
\hline F12 & & & $\begin{array}{l}\text { Precariedad } \\
\text { económica }\end{array}$ & & & $\begin{array}{l}\text { Precariedad } \\
\text { económica }\end{array}$ \\
\hline
\end{tabular}

Fuente: Elaboración propia.

En la Tabla 5 se muestra un resumen de los resultados obtenidos, indicando qué grupos tienen una mayor o menor vulnerabilidad en cada factor ${ }^{11}$ :

- El factor "desempleo" viene definido por las variables "parado" e "inactivo reciente". En él las personas que presentan una intensidad alta son solteros, tanto hombres como mujeres, con edades comprendidas entre 16 y 29 años. La nacionalidad de los varones es no perteneciente a España ni a la UE en 2005 y 2007, mientras que en el caso de las mujeres es en 2009 cuando no pertenecen a estos países. Respecto a la ocupación se encuentra una intensidad alta solamente en 2009 entre los varones que pertenecen a los grupos 7 (artesanos y trabajadores de las industrias manufactureras, la

${ }^{11}$ Por simplificar la exposición no se detalla aquellos factores relacionados con el ámbito de la vivienda por tener una menor incidencia estas variables. 
construcción y la minería excepto los operadores de instalaciones y maquinaria) y 9 (trabajadores no cualificados).

- Presentan una incidencia de intensidad moderada en este factor todas las mujeres entre 30 y 44 años y los varones de la misma edad pero solo en 2007 y 2009. Los separados de ambos sexos en 2009, las mujeres separadas y los divorciados y divorciadas en 2005 también pertenecen a este grupo, al igual que en 2005 y 2007, las mujeres de la Unión Europea y en 2009 los varones de la UE y las mujeres del resto del mundo. Los sectores de ocupación que presentan una incidencia de intensidad moderada son el 5 (trabajadores de servicios de restauración, personales de protección y vendedores de los comercios), el 6 (trabajadores cualificados en la agricultura y en la pesca) y el 8 (operadores y montadores de instalaciones y maquinaria fija y conductores) para la mujer en 2005 y 2007 y el 9 para ambos sexos y en los mismos años anteriores.

- A partir de las variables "sin experiencia laboral" y "trabajo domestico y familiar" surge el factor "nivel laboral bajo", que presenta una incidencia con intensidad alta, en los tres años en estudio, para las mujeres mayores de 44 años, casadas o viudas, de cualquier nacionalidad (salvo en 2005) y lugar de residencia (grado de urbanización).

- En el factor "precariedad laboral" se agrupan las variables "empleo bajo salario", "contrato temporal" y "pobre". Es un factor muy claro de vulnerabilidad laboral ya que esta forma de precariedad deja a los individuos en una situación de desprotección alta. Afecta con intensidad moderada a las mujeres menores de 45 años y a los hombres de 45 a 64 años. En los dos primeros años del periodo involucra a los solteros de ambos sexos y a las mujeres no pertenecientes a la UE. Si la mujer reside en una zona poco poblada presenta una intensidad moderada todos los años, mientras que si es hombre, la intensidad es alta. Respecto al sector de ocupación existe una intensidad alta en 2007 y 2009 entre los trabajadores de los sectores 1 y 6 y moderada en el 5 .

- El factor "percepción subjetiva" aglutina a las variables: "pobreza subjetiva", "imprevistos", "vacaciones" y "carga gastos vivienda" e informa de la percepción que tienen los individuos de carencias de tipo económico como el tener dificultad para llegar a fin de mes, o para pagar imprevistos, o para irse de vacaciones al menos una vez al año.

- Afecta en mayor medida a los jóvenes, de ambos sexos, entre 16 y 29 años, de países no pertenecientes a la UE, trabajadores no cualificados y mujeres separadas o divorciadas. La intensidad moderada se encuentra entre los solteros de ambos sexos, hombres separados y mujeres viudas, y a partir de 2007 con una edad entre 30 y 44 años. Afecta, si son mujeres, a los sectores de ocupación 5 y 8 ; y si son hombres al 7 y 8 . 
- El factor "nivel formativo bajo" incluye "estudios obligatorios completos", "sin estudios obligatorios ni formación en cursos" y "estudios básicos". Los grupos sociales que se ven más afectados por esta situación son los viudos de ambos sexos mayores de 64 años que habitan en zonas poco pobladas y cuyo grupo de ocupación es el 6 (aunque en 2007 la incidencia de este grupo es moderada). En 2005, tienen una intensidad alta las mujeres pertenecientes al sector de ocupación 7, 8 ó 9 (en este último caso también los varones), pasando a moderada en los dos últimos años, situación que comparten los varones del sector 7 y 8 que habitan en zonas medias, tienen nacionalidad comunitaria, están casados y con edad comprendida entre 45 y 64 años.

- El factor "enfermedad o discapacidad" hace referencia a un conjunto de situaciones de enfermedad y discapacidad que limitan la autonomía individual de las personas que las padecen e impide, en cierta medida, el desarrollo normal de cualquier actividad.

- Afecta en mayor intensidad a los viudos de ambos sexos, mayores de 64 años y a los trabajadores cuyo sector de ocupación es el 6 . De forma moderada a todas las mujeres independientemente de la zona en la que habiten y cuyo trabajo se desarrolla en los sectores 7, 8 o 9. En los dos últimos años, ser mujer separada o divorciada presenta una incidencia de intensidad moderada.

- Las carencias necesarias en el hogar al que pertenece un individuo se recogen en el factor "necesidades básicas" que incluye a las variables "televisor", "teléfono", "lavadora", "necesidades alimentarias" y "coche".

- Presentan una incidencia moderada en este factor los mayores de 64 años de ambos sexos y en 2005 también los jóvenes entre 16 y 29. Esta situación aparece en los individuos solteros y en el resto de colectivos salvo hombres separados y mujeres viudas en 2005. Los varones que habitan en zonas poco pobladas pertenecen a este grupo los tres años, los de zonas medias en los dos últimos años y los de zonas muy pobladas en 2009. En este último año son muchos los sectores de ocupación que presentan intensidad moderada.

- El factor "precariedad económica" incluye a los individuos que reciben ayuda familiar del Estado y que trabajan a tiempo parcial. Las mujeres entre 16 y 44 años que están casadas o separadas y pertenecen a los grupos de ocupación 5, 6 o 9 presentan una incidencia alta. Es también este sexo, a partir de los 45 años, solteras o divorciadas y cuyo sector de ocupación es el 3, 4 o 7 el que tiene una incidencia moderada. 
Tabla 5

Incidencia de los principales factores de exclusión

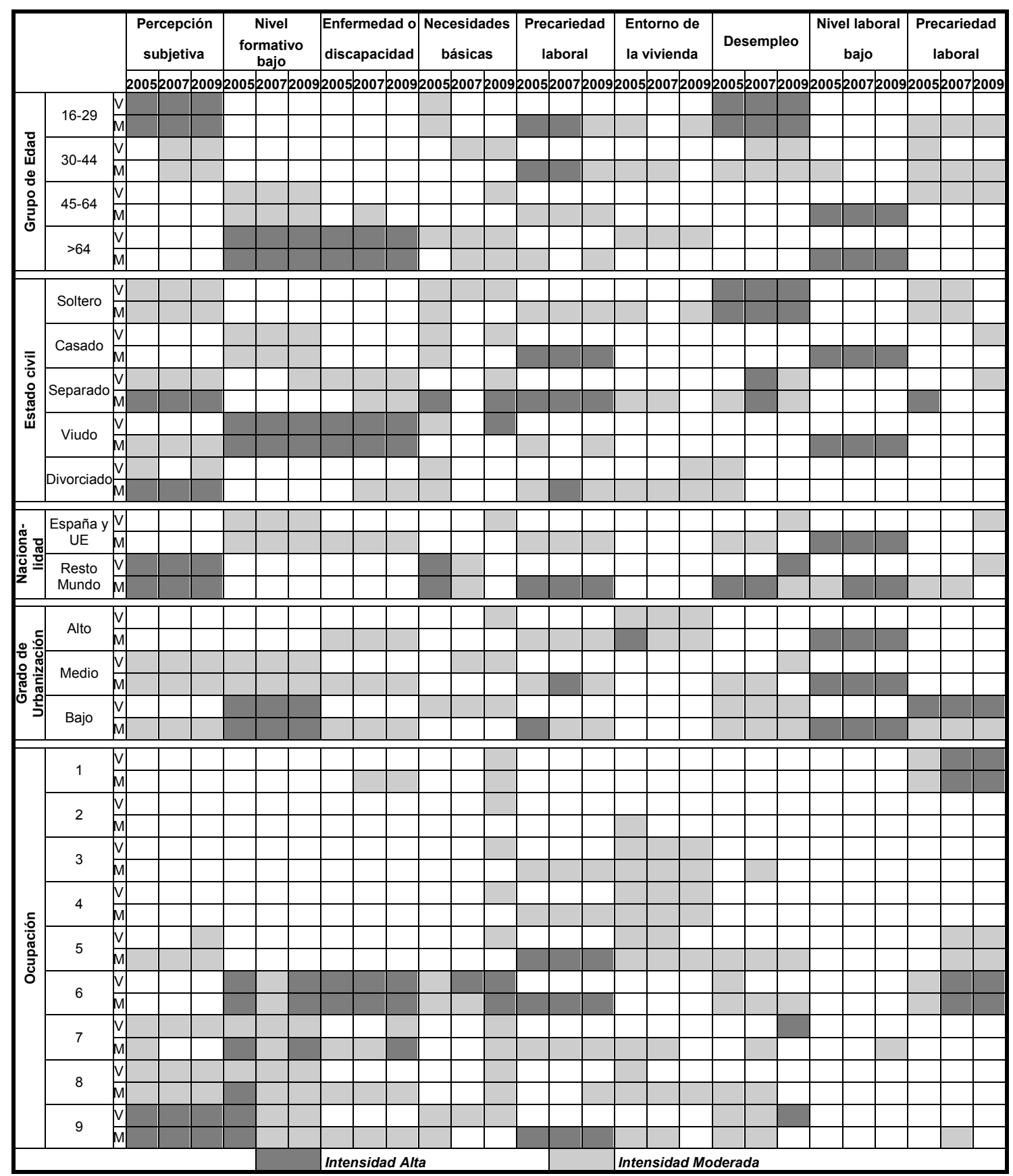

Fuente: Elaboración propia. 
- El último factor de vulnerabilidad, "entorno de la vivienda", recoge distintos aspectos que pueden influir en el bienestar del hogar de un individuo tales como los ruidos de vecinos o del exterior de la vivienda, problemas medioambientales producidos por la industria o el tráfico y delincuencia o vandalismo en la zona. En las zonas muy pobladas alcanza una intensidad superior a las demás.

\section{PERFIL DE LOS INDIVIDUOS VULNERABLES}

Una vez identificadas las personas vulnerables se establece un perfil de las mismas (para 2005, 2007 y 2009), mediante el análisis de conglomerados o análisis cluster ${ }^{12}$, tomando como variables estructurales el sexo, grupos de edad, estado civil, grado de urbanización, nacionalidad y ocupación.

Mediante esta técnica estadística se clasifican a los individuos en grupos homogéneos, de manera que aquéllos que tengan características similares sean asignados a un mismo cluster, y los que sean diferentes se sitúan en grupos distintos. Los resultados que se presentan a continuación son estables, es decir, efectuado el análisis de conglomerados para distintas ordenaciones de los casos, la solución obtenida no depende de ellas.

En 2005, una vez realizado el análisis cluster en función de los factores de vulnerabilidad aparecen cuatro conglomerados. Con el objetivo de buscar perfiles de vulnerabilidad definidos más claramente se ha llevado a cabo un nuevo análisis cluster para los individuos de cada conglomerado. El perfil de estos grupos aparece en la Tabla 6.

- La mayor parte de los adultos vulnerables (58,3\%), conglomerado 1, tienen como rasgo común su bajo nivel educativo. Si se desglosa este amplio conglomerado se observan dos subgrupos de diferente tamaño. El más numeroso sufre, principalmente, problemas de equipamiento sanitario de la vivienda y el otro presenta un cúmulo de problemas relacionados con la percepción subjetiva del individuo, desempleo, y de satisfacción de necesidades básicas.

- El segundo conglomerado contiene al $25 \%$ de vulnerables y el factor de exclusión predominante es el de precariedad laboral. Si se desagrega este conglomerado, sobresale su heterogeneidad, ya que aparecen cuatro subgrupos. El primero de ellos, el más numeroso adolece sobre todo de problemas educativos, El subgrupo 2.2 sufre problemas de equipamiento sanitario de la vivienda, el 2.3 problemas de desempleo y el 2.4 problemas de recursos y no tiene cubiertas las necesidades básicas.

\footnotetext{
${ }^{12}$ Se ha utilizado el paquete estadístico SPSS. La distancia utilizada para estudiar la similaridad entre los conglomerados ha sido la log-verosimilitud.
} 
- El conglomerado 3 se caracteriza por tener problemas de precariedad económica. Se distinguen dos subgrupos de tamaño similar, el primero con problemas relacionados además con la precariedad laboral, la pobreza y el equipamiento sanitario de la vivienda.

- El conglomerado 4 presenta problemas de desempleo. Hay dos subgrupos diferenciados, el primero con precariedad laboral y nivel laboral bajo y en el segundo destaca el desempleo.

Tabla 6

Perfil de los conglomerados en 2005

\begin{tabular}{|c|c|c|}
\hline \multirow{2}{*}{$\begin{array}{l}\text { Congl. } 1 \\
(58,3 \%)\end{array}$} & $\begin{array}{c}1.1 \\
(74,8 \%)\end{array}$ & $\begin{array}{l}\text { Mujeres, viudas, habitan en zona muy poblada, españolas o de U.E., mayores de } 64 \\
\text { años y grupo de ocupación } 8 .\end{array}$ \\
\hline & $\begin{array}{c}1.2 \\
(25,2 \%)\end{array}$ & $\begin{array}{l}\text { Hombres, solteros y separados, habitan en zona media, pertenecen al resto del } \\
\text { mundo, de } 16 \text { a } 29 \text { años y grupo } 9 \text {. }\end{array}$ \\
\hline \multirow{4}{*}{$\begin{array}{l}\text { Congl. } 2 \\
(25,0 \%)\end{array}$} & $\begin{array}{c}2.1 \\
(49,8 \%)\end{array}$ & $\begin{array}{l}\text { Hombres, casados, habitan en zona poco poblada, españoles de } 45 \text { a } 64 \text { años y grupo } \\
\text { de ocupación } 6 .\end{array}$ \\
\hline & $\begin{array}{c}2.2 \\
(19,5 \%)\end{array}$ & $\begin{array}{l}\text { Mujeres, separadas, habitan en zona muy poblada, proceden del resto del mundo, } \\
\text { menores de } 45 \text { años y grupo } 2 \text {. }\end{array}$ \\
\hline & $\begin{array}{c}2.3 \\
(16,8 \%)\end{array}$ & $\begin{array}{l}\text { Hombres, divorciados separados y solteros, habitan en zona muy poblada, proceden } \\
\text { del resto del mundo, menores de } 45 \text { años y grupo } 8 \text {. }\end{array}$ \\
\hline & $\begin{array}{c}2.4 \\
(14,0 \%)\end{array}$ & $\begin{array}{l}\text { Hombres, divorciados y solteros, habitan en zona muy poblada, proceden del resto del } \\
\text { mundo, menores de } 45 \text { años y grupo } 5 \text {. }\end{array}$ \\
\hline \multirow{2}{*}{$\begin{array}{l}\text { Congl. } 3 \\
(8,4 \%)\end{array}$} & $\begin{array}{c}3.1 \\
(50,3 \%)\end{array}$ & $\begin{array}{l}\text { Hombres, divorciados, separados y solteros, habitan en zona poco poblada, proceden } \\
\text { del resto del mundo, con } 16 \text { a } 29 \text { años y grupo } 2 \text {. }\end{array}$ \\
\hline & $\begin{array}{c}3.2 \\
(49,7 \%)\end{array}$ & $\begin{array}{l}\text { Mujeres, viudas, habitan en zona poco poblada, españolas o de U.E., mayores de } 64 \\
\text { años y grupo de ocupación } 6 .\end{array}$ \\
\hline \multirow{2}{*}{$\begin{array}{c}\text { Congl. } 4 \\
(8,3 \%)\end{array}$} & $\begin{array}{c}4.1 \\
(44,7 \%)\end{array}$ & $\begin{array}{l}\text { Hombres, divorciados y solteros, habitan en zona poco poblada, proceden del resto } \\
\text { del mundo, menores de } 45 \text { años y grupo } 2 \text {. }\end{array}$ \\
\hline & $\begin{array}{c}4.2 \\
(55,3 \%)\end{array}$ & $\begin{array}{l}\text { Hombres, solteros, habitan en zona media, proceden del resto del mundo, menores de } \\
45 \text { años y grupo } 2 \text {. }\end{array}$ \\
\hline
\end{tabular}

Fuente: Elaboración propia.

Realizado el análisis de conglomerados en función de los factores, aparecen en 2007, tres grupos. Al igual que en 2005, se lleva a cabo también otro análisis cluster para cada uno de los conglomerados y su caracterización en función de distintas variables puede consultarse en la Tabla 7.

- El cluster más numeroso (57,5\%), presenta un bajo nivel educativo, y se distinguen dos subgrupos de desigual tamaño. El que tiene un mayor porcentaje, sufre principalmente carencias en el equipamiento sanitario de la vivienda, mientras que el segundo se enfrenta a problemas múltiples, relacionados con la falta de bienes satisfactores de necesidades principales y secundarias. 
- El siguiente conglomerado en tamaño (35,5\%), tiene problemas relacionados con la precariedad laboral y el desempleo, y se caracteriza por su gran heterogeneidad interna, ya que se pueden distinguir hasta cinco subgrupos diferentes, de similar tamaño. El de mayor porcentaje adolece, principalmente, de precariedad laboral, y el cuarto tiene problemas de salud o discapacidad; mientras que los otros tres subgrupos poseen desventajas múltiples, diferentes en su composición e importancia relativa.

Tabla 7

Perfil de los conglomerados en 2007

\begin{tabular}{|c|c|c|}
\hline \multirow{5}{*}{$\begin{array}{l}\text { Congl. } 1 \\
(35,5 \%)\end{array}$} & $\begin{array}{c}1.1 \\
(21,1 \%)\end{array}$ & $\begin{array}{l}\text { Mujeres, divorciadas, solteras y separadas, habitan en zona muy poblada, del resto del } \\
\text { mundo, de } 16 \text { a } 44 \text { años y grupo de ocupación } 1 .\end{array}$ \\
\hline & $\begin{array}{c}1.2 \\
(26,8 \%)\end{array}$ & $\begin{array}{l}\text { Hombres, casados, habitan en zona poco poblada, pertenecen a la UE, de } 30 \text { a } 44 \text { años } \\
\text { y grupo } 2 \text {. }\end{array}$ \\
\hline & $\begin{array}{c}1.3 \\
(13,3 \%)\end{array}$ & $\begin{array}{l}\text { Hombres, separados, habitan en zonas poco pobladas, del resto del mundo, de } 16 \text { a } 29 \\
\text { años y grupo de ocupación } 3 .\end{array}$ \\
\hline & $\begin{array}{c}1.4 \\
(15,2 \%)\end{array}$ & Hombres, divorciados, del resto del mundo, de 16 a 44 años y grupo de ocupación 3. \\
\hline & $\begin{array}{c}1.5 \\
(23,5 \%)\end{array}$ & $\begin{array}{l}\text { Hombres, separados, habitan en zonas poco pobladas, de UE, de } 16 \text { a } 29 \text { años y grupo } \\
\text { de ocupación } 3 \text {. }\end{array}$ \\
\hline \multirow{2}{*}{$\begin{array}{l}\text { Congl. } 2 \\
(57,5 \%)\end{array}$} & $\begin{array}{c}2.1 \\
(21,6 \%) \\
\end{array}$ & $\begin{array}{l}\text { Hombres, separados o divorciado, habitan en zona media, del resto del mundo, de } 30 \text { a } \\
44 \text { años y grupo de ocupación } 4 \text {. }\end{array}$ \\
\hline & $\begin{array}{c}2.2 \\
(78,4 \%)\end{array}$ & Mujeres, viudas, habitan en zona muy poblada, de UE, mayores de 64 años y grupo 4. \\
\hline \multirow{2}{*}{$\begin{array}{l}\text { Congl. } 3 \\
(7 \%)\end{array}$} & $\begin{array}{c}3.1 \\
(47,8 \%)\end{array}$ & $\begin{array}{l}\text { Mujeres, viudas, habitan en zona poco poblada o media, de UE, mayores de } 64 \text { años y } \\
\text { grupo de ocupación } 2 \text {. }\end{array}$ \\
\hline & $\begin{array}{c}3.2 \\
(52,2 \%)\end{array}$ & $\begin{array}{l}\text { Hombres, solteros, habitan en zona poco poblada, del resto del mundo, mayores de } 64 \\
\text { años y grupo } 4 .\end{array}$ \\
\hline
\end{tabular}

Fuente: Elaboración propia.

- El conglomerado 3, cuyo tamaño es muy reducido (7\%), también se enfrenta a desventajas relacionadas con la precariedad económica y la satisfacción de necesidades básicas siendo cada una de ellas las características de cada subgrupo que lo forma.

Se repite este estudio en 2009 (Tabla 8). La crisis económica ha propiciado un aumento de la heterogeneidad del colectivo de vulnerabilidad social, ya que, de nuevo, se pueden distinguir 4 conglomerados. Cabe destacar otro cambio asociado a la crisis económica, y es el resurgimiento del problema del desempleo, que es el problema fundamental al que se enfrenta el conglomerado 4, que contiene al 23,5\% del total de adultos vulnerables. De todos modos, el factor de exclusión más destacado es el bajo nivel educativo, que permite la configuración del conglomerado más numeroso $(47,7 \%)$. Similar en tamaño al conglomerado de parados, aparece el 2, cuyo factor de exclusión principal es la inactividad. En el cluster número $3(5,5 \%)$ está presente de forma permanente, 
la precariedad económica. Se realiza un nuevo análisis cluster para cada uno de los conglomerados obteniendo los siguientes resultados:

Tabla 8

Perfil de los conglomerados en 2009

\begin{tabular}{|c|c|c|}
\hline \multirow{4}{*}{$\begin{array}{l}\text { Congl. } 1 \\
(47,7 \%)\end{array}$} & $\begin{array}{c}1.1 \\
(27,0 \%)\end{array}$ & $\begin{array}{l}\text { Hombres, casados, habitan en zona poco poblada, españoles o de UE, mayores de } 64 \\
\text { años y grupo de ocupación } 6 .\end{array}$ \\
\hline & $\begin{array}{c}1.2 \\
(26,1 \%)\end{array}$ & $\begin{array}{l}\text { Hombres, separados y divorciados, habitan en zona muy poblada, pertenecen al resto } \\
\text { del mundo, menores de } 65 \text { años y grupo } 9 \text {. }\end{array}$ \\
\hline & $\begin{array}{c}1.3 \\
(41,4 \%)\end{array}$ & $\begin{array}{l}\text { Hombres, viudos, habitan en zona muy poblada o media, de UE, mayores de } 64 \text { años } \\
\text { y grupo } 8 \text {. }\end{array}$ \\
\hline & $\begin{array}{c}1.4 \\
(5,5 \%)\end{array}$ & $\begin{array}{l}\text { Hombres, separados o divorciados, habitan en zona media, proceden del resto del } \\
\text { mundo, de } 45 \text { a } 64 \text { años y grupo } 8 .\end{array}$ \\
\hline \multirow{4}{*}{$\begin{array}{l}\text { Congl. } 2 \\
(23,3 \%)\end{array}$} & $\begin{array}{c}2.1 \\
(34,0 \%)\end{array}$ & $\begin{array}{l}\text { Mujeres, viudas, habitan en zona muy poblada, de la UE, mayores de } 64 \text { años y grupo } \\
6 .\end{array}$ \\
\hline & $\begin{array}{c}2.2 \\
(44,9 \%)\end{array}$ & $\begin{array}{l}\text { Mujeres, casadas y solteras, habitan en zona poco poblada, de la UE, mayores de } 64 \\
\text { años y grupo } 9 .\end{array}$ \\
\hline & $\begin{array}{c}2.3 \\
(18,1 \%)\end{array}$ & $\begin{array}{l}\text { Mujeres, casadas, habitan en zona media, del resto del mundo, de } 16 \text { a } 29 \text { años y } \\
\text { grupo } 9 .\end{array}$ \\
\hline & $\begin{array}{c}2.4 \\
(3,0 \%) \\
\end{array}$ & $\begin{array}{l}\text { Mujeres, casadas, habitan en zona media, del resto del mundo, mayores de } 64 \text { años y } \\
\text { grupo } 8 .\end{array}$ \\
\hline \multirow{2}{*}{$\begin{array}{l}\text { Congl. } 3 \\
(5,5 \%)\end{array}$} & $\begin{array}{c}3.1 \\
(67,4 \%)\end{array}$ & $\begin{array}{l}\text { Mujeres, separadas y viudas, habitan en zona poco poblada, de la UE, mayores de } 64 \\
\text { años y grupo } 6 .\end{array}$ \\
\hline & $\begin{array}{c}3.2 \\
(32,6 \%) \\
\end{array}$ & $\begin{array}{l}\text { Hombres, separados y solteros, habitan en zona muy poblada, proceden del resto del } \\
\text { mundo, con } 30 \text { a } 44 \text { años y grupo } 2 \text {. }\end{array}$ \\
\hline \multirow{2}{*}{$\begin{array}{l}\text { Congl. } 4 \\
(23,5 \%)\end{array}$} & $\begin{array}{c}4.1 \\
(72 \%)\end{array}$ & $\begin{array}{l}\text { Hombres, solteros y divorciados, habitan en zona media, proceden del resto del } \\
\text { mundo, menores de } 45 \text { años y grupo } 6 \text {. }\end{array}$ \\
\hline & $\begin{array}{c}4.2 \\
(28,0 \%)\end{array}$ & $\begin{array}{l}\text { Hombres, casados, habitan en zona muy poblada, proceden del resto del mundo, } \\
\text { menores de } 45 \text { años y grupo } 2 \text {. }\end{array}$ \\
\hline
\end{tabular}

Fuente: Elaboración propia.

- El conglomerado 1 es muy heterogéneo, ya que se pueden distinguir hasta 4 subgrupos. El más numeroso de ellos $(41,4 \%)$ se caracteriza por estar afectado del problema de precariedad económica. En el primero se añade la precariedad laboral, el segundo no tiene cubiertas las necesidades básicas y en el cuarto, problemas de equipamiento.

- En el conglomerado $2(23,3 \%)$ cabe distinguir hasta 4 subgrupos diferentes. El más numeroso presenta, principalmente, el problema de precariedad laboral y de pobreza. En el segundo subgrupo $(34,0 \%)$ el problema fundamental es el bajo nivel educativo.

- El conglomerado 3, está afectado por el problema de precariedad económica, y es más homogéneo que los anteriores, ya que se pueden distinguir dos subgrupos de tamaño diferente. Esta desventaja predomina en el subgrupo más numeroso, mientras que en el otro se encuentra una pluralidad 
de desventajas sociales: precariedad laboral y pobreza, problemas de cobertura de necesidades secundarias, y problemas relacionados con el entorno de la vivienda.

- El conglomerado 4 se divide en dos subgrupos. El más numeroso afectado por dos problemas principales, el desempleo, que es el rasgo común del conglomerado, y el bajo nivel educativo. El otro subgrupo se enfrenta a múltiples desventajas sociales, relacionadas con la inserción laboral, con problemas de precariedad laboral y pobreza, de inactividad prolongada por haberse dedicado a las faenas domésticas, y está presente el problema de la enfermedad o la discapacidad.

\section{MEDICIÓN DEL RIESGO A LA EXCLUSIÓN SOCIAL}

Hay múltiples procedimientos de estimación del riesgo a la exclusión social, y en este trabajo se han utilizado diferentes medidas del mismo, aunque complementarias por la información que ofrecen.

En la Tabla A1 del anexo se tiene el porcentaje de individuos vulnerables por colectivos o equivalentemente, el valor del índice $\mathrm{H}$ definido como la tasa de riesgo de exclusión para cada categoría de las variables estructurales analizadas en cada uno de los años considerados distinguiendo por sexo.

Los colectivos con más tasa de riesgo de exclusión, independientemente del año estudiado, son principalmente mujeres, mayores de 64 años, viudas, que proceden del resto del mundo, residentes en zonas poco pobladas y cuya última ocupación ha sido la agricultura o la pesca.

Se calcula un nuevo indicador, $\mathrm{V}$, para medir el grado de vulnerabilidad media del colectivo de vulnerables, expresado en proporción del valor máximo de vulnerabilidad para cada uno de los años en estudio. Para cada adulto vulnerable se calcula el índice $\mathrm{V}_{\mathrm{i}}$ cuya expresión analítica es:

$$
V_{i}=\frac{S_{i}}{n \max _{j} \frac{w_{j}}{\sum_{j=1}^{n} w_{j}} P_{i j}}
$$

siendo $S_{i}$ la suma ponderada de las puntuaciones factoriales del individuo $i, n$ el número de factores, $P_{i j}$ la puntuación factorial del factor $j$ en el individuo $i \mathrm{y}$ $w_{j}$ el porcentaje de varianza explicada por el factor $\mathrm{j}$ una vez rotado. Obtenido este índice para todos los individuos se calcula su media para cada grupo social en estudio y los resultados se recogen en la Tabla A2 del anexo. Esta medida da cuenta de la intensidad de la vulnerabilidad por colectivos. 
Los colectivos con un mayor grado de vulnerabilidad a la exclusión en 2005 son las mujeres mayores de 64 años, que están separadas, con nacionalidad española o de algún país de la Unión Europea, viven en zonas medias pobladas y cuya última ocupación es la de trabajadora no cualificada.

En 2007, el perfil del colectivo más vulnerable es igual que en 2005, aunque el valor de la medida es un poco inferior, es decir, se aprecia una leve mejoría en este periodo. Sin embargo, en 2009, el índice vuelve a subir presentando valores superiores a 2005. En este último año el grupo con mayor intensidad a la vulnerabilidad, en promedio, son las mujeres separadas, mayores de 64 años, de nacionalidad fuera de la UE, que residen en zonas poco pobladas y cuya ocupación es la de trabajadora cualificada en la agricultura o en la pesca.

A partir de las dos dimensiones básicas de la privación multidimensional, la incidencia, o la proporción de personas vulnerables dentro de cada colectivo (Tabla A1), y la intensidad, o grado de vulnerabilidad social al que se enfrenta cada grupo (Tabla A2), se calcula el índice ponderado de riesgo de exclusión mediante una expresión similar a la utilizada por el PNUD (Programa de la Naciones Unidas para el Desarrollo) en el cálculo del índice de pobreza multidimensional:

$$
R_{i}=H_{i} \cdot V_{i}
$$

siendo: $H_{i}$ la tasa de riesgo del colectivo $i$ y $V_{i}$ el grado de vulnerabilidad media del colectivo de vulnerables, expresado en proporción del valor máximo de vulnerabilidad.

Esta medida del riesgo no sólo tiene en cuenta la probabilidad de superar el nivel de riesgo socialmente crítico, sino también el grado con que una persona ha superado dicho umbral. Es una medida diseñada para reflejar las graves carencias que sufren de forma simultánea las personas, que recoge tanto la incidencia de estas carencias multidimensionales como su intensidad, es decir, cuántas carencias se sufren al mismo tiempo.

Observando la Tabla A3 del anexo, se puede concluir que los colectivos con un mayor riesgo de exclusión ponderado son, en 2005, mujeres mayores de 64 años, viudas, de nacionalidad española o de algún país de la UE, que viven en zonas poco pobladas y cuya última ocupación ha sido en la agricultura o la pesca.

El perfil de un individuo con riesgo de exclusión en 2007 sigue siendo el de mujer, viuda mayor de 64 años, que procede de países no comunitarios, residen en zonas poco pobladas y el sector de ocupación en este año es el de trabajos de baja cualificación. En 2009 se mantienen las mismas características salvo el sector de ocupación (mujer trabajadora en la agricultura o en la pesca). 


\section{CONCLUSIONES}

Este trabajo ofrece información sobre las características de las personas adultas vulnerables a la exclusión social en España, durante el período 20042009, utilizando la información recogida en las Encuestas de Condiciones de Vida para estos años.

Los resultados obtenidos permiten comprender el fenómeno de la exclusión social a través de la identificación de los elementos que intervienen en los procesos de exclusión y los colectivos vulnerables a dichos procesos, analizando también la extensión y la intensidad del fenómeno. Hay que tener en cuenta que los indicadores de exclusión no deben considerarse como reflejo de situaciones de exclusión por sí mismos, son indicadores de vulnerabilidad o riesgo de exclusión y la acumulación de los mismos es lo que determinará que un individuo pueda ser considerado vulnerable a la exclusión social.

La vulnerabilidad a la exclusión social se define como una situación de precariedad social multidimensional, manifestada en los ámbitos económico, laboral, ambiental, formativo, salud y vivienda. Se ha trabajado con variables agrupadas en estos ámbitos para encontrar, a través del análisis factorial, los factores de exclusión social. Se han identificado 11 factores para todos los años en estudio (excepto para 2006 y 2009 en los que se obtienen 12) que recogen aspectos tales como la percepción subjetiva del individuo, su nivel formativo, su capacidad financiera, su estado de salud, las condiciones físicas de la vivienda y el entorno, entre otros.

Se ha identificado la vulnerabilidad a la exclusión social en aquellas personas susceptibles de sufrir exclusión en el futuro. Los grupos vulnerables a la exclusión social son los que tienen riesgo de alcanzar un nivel de vulnerabilidad superior a cierto valor socialmente crítico, que en el trabajo se ha establecido en el percentil 70 de la distribución de los individuos que presentan una acumulación de factores de vulnerabilidad.

Se ha estudiado la incidencia de los factores más destacados en distintos grupos sociales (por grupos de edad de los individuos, su estado civil, la nacionalidad, grado de urbanización de la vivienda de residencia y ocupación) todos ellos diferenciando por sexo, para 2005, 2007 y 2009. Entre los resultados obtenidos destacan:

- La existencia de tres factores con un contenido claro de vulnerabilidad laboral: "desempleo", "nivel laboral bajo" y "precariedad laboral". Los individuos con edades comprendidas entre 16 y 29 años, solteros, que proceden de países no ambientales presentan una incidencia alta en el primero de ellos, que aumenta con el trascurso de los años. Presentan una intensidad alta en los tres años en estudio las mujeres mayores de 44 años, que están casadas o viudas, de cualquier nacionalidad y lugar de residen- 
cia (grado de urbanización) en el segundo factor, y la "precariedad laboral" aparece en 2007 y 2009 entre los trabajadores cualificados en la agricultura y la pesca.

- La vulnerabilidad económica se podría explicar con los factores "percepción subjetiva", "necesidades básicas" y "precariedad económica". Los dos primeros afectan en mayor medida a los jóvenes entre 16 y 29 años del mismo sexo, de países no comunitarios y trabajo no cualificado, mientras que el último aparece con mayor intensidad en las mujeres menores de 45 años que están casadas o separadas.

- Factores como "nivel formativo bajo", "enfermedad o discapacidad" y "entorno de la vivienda" describen la vulnerabilidad social. Los grupos sociales que se ven afectados por esta situación son los viudos, de ambos sexos, mayores de 64 años.

A través del análisis cluster se ha clasificado a los individuos en grupos homogéneos con características similares. En 2005 se han obtenido cuatro grupos caracterizados por los siguientes factores de vulnerabilidad: "bajo nivel educativo", "precariedad laboral", "precariedad económica" y "desempleo". En 2007 hay tres conglomerados, donde aparecen los problemas del "bajo nivel educativo", precariedad laboral" junto con el "desempleo" y, en el último, además, "precariedad económica". La actual crisis económica ha favorecido el aumento de la heterogeneidad del colectivo de vulnerables en 2009 ya que aparecen nuevamente cuatro conglomerados.

La aplicación de esta técnica estadística ha permitido encontrar, para las personas adultas definidas previamente como vulnerables, unos perfiles de vulnerabilidad que afectan a distintos colectivos de una forma diferenciada.

Los individuos adultos con un mayor riesgo de exclusión social son, en 2005, las mujeres mayores de 64 años, viudas, de nacionalidad española o de algún país comunitario, que viven en zonas poco pobladas y cuya última ocupación ha sido en la agricultura o la pesca. En 2007 se mantiene el mismo perfil salvo el sector de ocupación que pasa a ser trabajador de baja cualificación. En el último año vuelve a aparecer como sector de ocupación dominante el de mujer trabajadora en la agricultura y la pesca.

Conocidos los distintos perfiles de vulnerabilidad y los individuos con un mayor riesgo de exclusión social se estará en condiciones de diseñar, para cada colectivo afectado, medidas que permitan que dicha exclusión no se produzca.

Esta línea de investigación se completará con los nuevos datos publicados en los últimos meses por el Instituto Nacional de Estadística, que incluye información exhaustiva de los hogares en 2010, y la pronta aparición de la ECV para 2011. Así mismo se está realizando un estudio de la vulnerabilidad a nivel te- 
rritorial intentando determinar el efecto que las distintas políticas sociales de la Comunidades Autónomas tienen sobre este fenómeno.

\section{REFERENCIAS BIBLIOGRÁFICAS}

BANCO MUNDIAL (2000). Informe sobre el desarrollo Mundial 2000-2001.

BRUGUE, Q; GOMA, R. y SUBIRATS, J. (2002). "De la pobreza a la exclusión social: nuevos retos para las políticas públicas", en Revista Internacional de Sociología, 33, pp. 7-45.

CES (1996). "La pobreza y la exclusión social en España”, en Sesión del Pleno de 22 de Noviembre de 1996.

CONSEJO ECONÓMICO Y SOCIAL DE CANARIAS (1998). Dictamen 1/1998, del Consejo Económico y Social de Canarias, preceptivo, solicitado por el Gobierno de Canarias, sobre el Plan de Integración Social contra la pobreza y la exclusión social en Canarias. http://www.cescanarias.org/publicaciones/ dictamenes/dic_1_98.html. [Último acceso: Abril de 2012]

CONSEJO EUROPEO DE LISBOA (2000). "Conclusiones de la Presidencia" http://www.europarl.europa.eu/summits/lis1_es.htm. [Último acceso: Abril de 2012]

CONSEJO EUROPEO DE SANTA MARÍA DA FEIRA (2000). Conclusiones de la Presidencia. http://www.europarl.europa.eu/summits/fei2_es.htm. [Último acceso: Abril de 2012]

DE HAAN, A. (2000). "Social Exclusion: Enriching the Understanding of Deprivation", en Studies in Social and Political Thought, 2 pp.22-40.

GARCÍA LIZANA A. y ZAYAS FUENTES, S.J. (2000). "Aproximación al concepto de exclusión social", en Anales de Economía Aplicada, XIV Reunión de Asepelt.

GIL, M. y ORTIZ, S. (2009). Determinantes de la pobreza extrema en España desde una doble perspectiva: monetaria y de privación. Estudios de Economía Aplicada, 27(2), 437-462.

HERNÁNDEZ PEDREÑO, M. (2008). "Exclusión social en la Región de Murcia. Aproximación cuantitativa y cualitativa”, en M. Hernández Pedreño (dir.), Exclusión social y desigualdad, Editum, Universidad de Murcia.

INFORME FOESSA (VI) (2008). Exclusión y Desarrollo Social en España. http://www.foessa.es/publicaciones_Info.aspx?Id=379 [Último acceso: Abril de 2012]

LAFUENTE, M., FAURA, U. y LOSA, A. (2011). "Medidas y caracterización de la vulnerabilidad a la exclusión social de los hogares en España" en Rect@, 12; pp.53-68. 
LAFUENTE, M. y FAURA, U. (2012). "Estudio de la vulnerabilidad a la exclusión social por Comunidades Autónomas en España” en Investigaciones Regionales (forthcoming)

LAPARRA, R. et al (2007), "Una propuesta de consenso sobre el concepto de exclusión. Implicaciones metodológicas", en Revista Española del Tercer Sector, 5 pp. 15-57.

MARTÍNEZ GONZÁLEZ, J.A. (2011). "Exclusión social y pobreza. El caso de Canarias", en Contribuciones a las Ciencias Sociales, http://www.eumed.net/rev/cccss/13/ [Último acceso: Abril 2012].

NUÑEZ, J.J. (2009). "Estado actual y nuevas aproximaciones a la medición de la pobreza", en Revista de Estudios de Economía Aplicada 27(2), pp. 325344.

PÉREZ, C. (2009). Técnicas estadísticas multivariantes con SPSS. Gaceta Grupo Editorial.

PERONA, N.B. y. ROCCHI, G.I. (2001). "Vulnerabilidad y Exclusión Social. Una propuesta metodológica para el estudio de las condiciones de vida de los hogares", en Kairos, 8.

POZA, C. (2008). Pobreza multidimensional: el caso específico español a través del panel de hogares de la Unión Europea, tesis doctoral.

SEN, A. (2000). "Social exclusion: Concept, Application and Scrutiny, Social Development" Paper 1 en Asian Development Bank, Manila.

SILVER, H. (1994). "Social Exclusion and Social Solidarity: Three Paradigms", en International Labor Review. 133 pp: 607-662.

SIMO, C.; SÁNCHEZ, I.; LLOPIS, R. y CASTELLO, R. (2011). "Conceptos, datos y métodos de la precariedad: propuesta de indicadores sintéticos". X Congreso AECPA, Grupo de trabajo 5.2: Políticas públicas y procesos de precarización social.

SUBIRATS, J. (director), RIBA, C.; GIMÉNEZ, L.; OBRADORS, A; GIMÉNEZ, M.; QUERALT, D.; BOTTOS, P. y RAPOPORT, A. (2004). "Pobreza y exclusión social. Un análisis de la realidad española y europea" en Colección de Estudios Sociales, $n^{\circ}$ 16, Fundación La Caixa. http://www.estudios.lacaixa.es [Último acceso: Abril de 2012].

SUBIRATS, J. (director) GOMA, R y BRUGUE, J. (coordinadores) (2005). "Análisis de los factores de exclusión social" en Documento de trabajo $\mathrm{n}^{\circ} 4$, Fundación BBVA. http://www.fbbva.es/TLFU/dat/exclusion_social.pdf [Último acceso: Abril 2012].

URIEL, E. (1995). Análisis de datos. Series temporales y Análisis multivariante. Ed. AC.

WHELAN, CH. y MAÎTRE, B. (2005). "Vulnerability and multiple deprivation perspectives on economic exclusion in Europe: A latent class analysis" en European Societies, 7(33), pp 423-450. 
ANEXO

Tabla A1

Tasa de riesgo de exclusión social por colectivos $(\mathrm{H})$

\begin{tabular}{|c|c|c|c|c|c|}
\hline & & & $\mathrm{H}_{2005}$ & $\mathrm{H}_{2007}$ & $\mathrm{H}_{2009}$ \\
\hline \multirow{8}{*}{ Grupos edad } & \multirow{2}{*}{$16-29$} & Hombre & 0,1324 & 0,1345 & 0,1661 \\
\hline & & Mujer & 0,1401 & 0,1553 & 0,1613 \\
\hline & \multirow{2}{*}{$30-44$} & Hombre & 0,1594 & 0,1678 & 0,1989 \\
\hline & & \begin{tabular}{|l} 
Mujer \\
\end{tabular} & 0,2153 & 0,2238 & 0,2044 \\
\hline & \multirow{2}{*}{$45-64$} & Hombre & 0,2288 & 0,2395 & 0,2495 \\
\hline & & Mujer & 0,3564 & 0,3610 & 0,3082 \\
\hline & \multirow{2}{*}{$>64$} & Hombre & 0,3304 & 0,3362 & 0,3253 \\
\hline & & Mujer & 0,5607 & 0,5352 & 0,5432 \\
\hline \multirow{10}{*}{ Estado civil } & \multirow{2}{*}{ Soltero } & Hombre & 0,1729 & 0,1819 & 0,2030 \\
\hline & & Mujer & 0,1769 & 0,1918 & 0,1695 \\
\hline & \multirow{2}{*}{ Casado } & Hombre & 0,2197 & 0,2227 & 0,2446 \\
\hline & & Mujer & 0,3283 & 0,3264 & 0,3146 \\
\hline & \multirow{2}{*}{ Separado } & Hombre & 0,2496 & 0,3171 & 0,3088 \\
\hline & & Mujer & 0,3866 & 0,4677 & 0,4200 \\
\hline & \multirow{2}{*}{ Viudo } & Hombre & 0,2621 & 0,3129 & 0,2793 \\
\hline & & Mujer & 0,5876 & 0,5627 & 0,5620 \\
\hline & \multirow{2}{*}{ Divorciado } & Hombre & 0,1806 & 0,2198 & 0,2095 \\
\hline & & Mujer & 0,3114 & 0,3909 & 0,3324 \\
\hline \multirow{4}{*}{ Nacionalidad } & \multirow{2}{*}{ España y UE } & Hombre & 0,2037 & 0,2108 & 0,2245 \\
\hline & & Mujer & 0,3202 & 0,3196 & 0,3014 \\
\hline & \multirow{2}{*}{ Resto Mundo } & Hombre & 0,2369 & 0,2467 & 0,3662 \\
\hline & & Mujer & 0,3228 & 0,3981 & 0,3907 \\
\hline \multirow{6}{*}{ Grado Urbanización } & \multirow{2}{*}{ Muy poblada } & Hombre & 0,1745 & 0,1754 & 0,1965 \\
\hline & & Mujer & 0,2922 & 0,2846 & 0,2662 \\
\hline & \multirow{2}{*}{ Media } & Hombre & 0,2108 & 0,2403 & 0,2576 \\
\hline & & Mujer & 0,3124 & 0,3440 & 0,3246 \\
\hline & \multirow{2}{*}{ Poco poblada } & Hombre & 0,2563 & 0,2603 & 0,2740 \\
\hline & & Mujer & 0,3818 & 0,3820 & 0,3708 \\
\hline \multirow{18}{*}{ Ocupación } & \multirow{2}{*}{1} & Hombre & 0,1454 & 0,1423 & 0,2006 \\
\hline & & Mujer & 0,2179 & 0,2830 & 0,3143 \\
\hline & \multirow{2}{*}{2} & Hombre & 0,0168 & 0,0314 & 0,0231 \\
\hline & & Mujer & 0,0255 & 0,0279 & 0,0254 \\
\hline & \multirow{2}{*}{3} & Hombre & 0,0617 & 0,0942 & 0,0983 \\
\hline & & Mujer & 0,1113 & 0,0939 & 0,0729 \\
\hline & \multirow{2}{*}{4} & Hombre & 0,0685 & 0,0836 & 0,0731 \\
\hline & & \begin{tabular}{|l|} 
Mujer \\
\end{tabular} & 0,0924 & 0,0982 & 0,0965 \\
\hline & 5 & Hombre & 0,1938 & 0,2070 & 0,1918 \\
\hline & 5 & Mujer & 0,2896 & 0,2946 & 0,2743 \\
\hline & & Hombre & 0,4060 & 0,4610 & 0,4454 \\
\hline & 6 & Mujer & 0,6255 & 0,6062 & 0,6352 \\
\hline & & Hombre & 0,2286 & 0,2505 & 0,3181 \\
\hline & $r$ & $\begin{array}{l}\text { Mujer } \\
\end{array}$ & 0,3520 & 0,3691 & 0,3768 \\
\hline & 8 & Hombre & 0,2293 & 0,2051 & 0,2375 \\
\hline & 8 & Mujer & 0,3308 & 0,3697 & 0,3303 \\
\hline & & Hombre & 0,3509 & 0,3573 & 0,3857 \\
\hline & 9 & Mujer & 0,4837 & 0,5178 & 0,4688 \\
\hline
\end{tabular}

Fuente: Elaboración propia. 
Tabla A2

Grado de vulnerabilidad social por grupos sociales (V)

\begin{tabular}{|c|c|c|c|c|c|}
\hline & & & $V_{2005}$ & $\mathbf{V}_{2007}$ & $V_{2009}$ \\
\hline \multirow{8}{*}{ Grupos edad } & \multirow{2}{*}{$16-29$} & Hombre & 0,1170 & 0,1164 & 0,1211 \\
\hline & & Mujer & 0,1196 & 0,1205 & 0,1259 \\
\hline & \multirow{2}{*}{$30-44$} & Hombre & 0,1194 & 0,1173 & 0,1148 \\
\hline & & Mujer & 0,1238 & 0,1226 & 0,1231 \\
\hline & \multirow{2}{*}{$45-64$} & Hombre & 0,1251 & 0,1240 & 0,1289 \\
\hline & & Mujer & 0,1339 & 0,1330 & 0,1384 \\
\hline & \multirow{2}{*}{$>64$} & Hombre & 0,1272 & 0,1251 & 0,1245 \\
\hline & & Mujer & 0,1374 & 0,1337 & 0,1410 \\
\hline \multirow{10}{*}{ Estado civil } & \multirow{2}{*}{ Soltero } & Hombre & 0,1183 & 0,1211 & 0,1214 \\
\hline & & Mujer & 0,1259 & 0,1277 & 0,1305 \\
\hline & \multirow{2}{*}{ Casado } & Hombre & 0,1264 & 0,1210 & 0,1231 \\
\hline & & Mujer & 0,1307 & 0,1266 & 0,1328 \\
\hline & \multirow{2}{*}{ Separado } & Hombre & 0,1064 & 0,1169 & 0,1296 \\
\hline & & Mujer & 0,1514 & 0,1486 & 0,1567 \\
\hline & \multirow{2}{*}{ Viudo } & Hombre & 0,1126 & 0,1393 & 0,1285 \\
\hline & & Mujer & 0,1371 & 0,1379 & 0,1414 \\
\hline & \multirow{2}{*}{ Divorciado } & Hombre & 0,1355 & 0,1188 & 0,1156 \\
\hline & & Mujer & 0,1413 & 0,1347 & 0,1457 \\
\hline \multirow{4}{*}{ Nacionalidad } & \multirow{2}{*}{ España y UE } & Hombre & 0,1232 & 0,1224 & 0,1227 \\
\hline & & Mujer & 0,1324 & 0,1307 & 0,1352 \\
\hline & \multirow{2}{*}{ Resto Mundo } & Hombre & 0,1216 & 0,1041 & 0,1227 \\
\hline & & Mujer & 0,1239 & 0,1179 & 0,1369 \\
\hline \multirow{6}{*}{ Grado Urbanización } & \multirow{2}{*}{ Muy poblada } & Hombre & 0,1272 & 0,1214 & 0,1211 \\
\hline & & Mujer & 0,1334 & 0,1301 & 0,1344 \\
\hline & \multirow{2}{*}{ Media } & Hombre & 0,1230 & 0,1234 & 0,1248 \\
\hline & & Mujer & 0,1341 & 0,1310 & 0,1347 \\
\hline & \multirow{2}{*}{ Poco poblada } & Hombre & 0,1182 & 0,1206 & 0,1233 \\
\hline & & Mujer & 0,1290 & 0,1293 & 0,1369 \\
\hline \multirow{18}{*}{ Ocupación } & \multirow{2}{*}{1} & Hombre & 0,1209 & 0,1267 & 0,1238 \\
\hline & & Mujer & 0,1127 & 0,1274 & 0,1371 \\
\hline & \multirow{2}{*}{2} & Hombre & 0,0851 & 0,0725 & 0,0743 \\
\hline & & Mujer & 0,0801 & 0,0871 & 0,0836 \\
\hline & \multirow{2}{*}{3} & Hombre & 0,1156 & 0,1143 & 0,1171 \\
\hline & & Mujer & 0,1074 & 0,1024 & 0,1183 \\
\hline & \multirow{2}{*}{4} & Hombre & 0,1076 & 0,1166 & 0,1023 \\
\hline & & Mujer & 0,1052 & 0,1029 & 0,1081 \\
\hline & 5 & Hombre & 0,1247 & 0,1168 & 0,1234 \\
\hline & 5 & Mujer & 0,1234 & 0,1225 & 0,1368 \\
\hline & & Hombre & 0,1142 & 0,1245 & 0,1335 \\
\hline & 6 & Mujer & 0,1284 & 0,1163 & 0,1554 \\
\hline & 7 & Hombre & 0,1202 & 0,1169 & 0,1170 \\
\hline & $r$ & Mujer & 0,1270 & 0,1362 & 0,1390 \\
\hline & 8 & Hombre & 0,1220 & 0,1162 & 0,1134 \\
\hline & 8 & Mujer & 0,1271 & 0,1294 & 0,1280 \\
\hline & & Hombre & 0,1242 & 0,1247 & 0,1285 \\
\hline & 9 & Mujer & 0,1364 & 0,1368 & 0,1445 \\
\hline
\end{tabular}

Fuente: Elaboración propia. 
Tabla A3

Índice ponderado de riesgo de exclusión (R)

\begin{tabular}{|c|c|c|c|c|c|}
\hline & & & $\mathbf{R}_{2005}$ & $\mathbf{R}_{\mathbf{2 0 0 7}}$ & $\mathbf{R}_{\mathbf{2 0 0 9}}$ \\
\hline \multirow{8}{*}{ Grupos edad } & \multirow{2}{*}{$16-29$} & Hombre & 0,0155 & 0,0157 & 0,0201 \\
\hline & & Mujer & 0,0168 & 0,0187 & 0,0203 \\
\hline & \multirow{2}{*}{$30-44$} & Hombre & 0,0190 & 0,0197 & 0,0228 \\
\hline & & Mujer & 0,0267 & 0,0274 & 0,0252 \\
\hline & \multirow{2}{*}{$45-64$} & Hombre & 0,0286 & 0,0297 & 0,0322 \\
\hline & & Mujer & 0,0477 & 0,0480 & 0,0427 \\
\hline & \multirow{2}{*}{$>64$} & Hombre & 0,042 & 0,0421 & 0,0405 \\
\hline & & Mujer & 0,0771 & 0,0715 & 0,0766 \\
\hline \multirow{10}{*}{ Estado civil } & \multirow{2}{*}{ Soltero } & Hombre & 0,0205 & 0,022 & 0,0246 \\
\hline & & Mujer & 0,0223 & 0,0245 & 0,0221 \\
\hline & \multirow{2}{*}{ Casado } & Hombre & 0,0278 & 0,0269 & 0,0301 \\
\hline & & Mujer & 0,0429 & 0,0413 & 0,0418 \\
\hline & \multirow{2}{*}{ Separado } & Hombre & 0,0266 & 0,0371 & 0,040 \\
\hline & & Mujer & 0,0585 & 0,0695 & 0,0658 \\
\hline & \multirow{2}{*}{ Viudo } & Hombre & 0,0295 & 0,0436 & 0,0359 \\
\hline & & Mujer & 0,0805 & 0,0776 & 0,0795 \\
\hline & \multirow{2}{*}{ Divorciado } & Hombre & 0,0245 & 0,0261 & 0,0242 \\
\hline & & Mujer & 0,0440 & 0,0526 & 0,0484 \\
\hline \multirow{4}{*}{ Nacionalidad } & \multirow{2}{*}{ España y UE } & Hombre & 0,0251 & 0,0258 & 0,0275 \\
\hline & & Mujer & 0,0424 & 0,0418 & 0,0407 \\
\hline & \multirow{2}{*}{ Resto Mundo } & Hombre & 0,0288 & 0,0257 & 0,0449 \\
\hline & & Mujer & 0,0400 & 0,0469 & 0,0535 \\
\hline \multirow{6}{*}{ Grado Urbanización } & \multirow{2}{*}{ Muy poblada } & Hombre & 0,0222 & 0,0213 & 0,0238 \\
\hline & & Mujer & 0,0390 & 0,037 & 0,0358 \\
\hline & \multirow{2}{*}{ Media } & Hombre & 0,0259 & 0,0297 & 0,0322 \\
\hline & & Mujer & 0,0419 & 0,0451 & 0,0437 \\
\hline & \multirow{2}{*}{ Poco poblada } & Hombre & 0,0303 & 0,0314 & 0,0338 \\
\hline & & Mujer & 0,0493 & 0,0494 & 0,0508 \\
\hline \multirow{18}{*}{ Ocupación } & \multirow{2}{*}{1} & Hombre & 0,0176 & 0,018 & 0,0248 \\
\hline & & Mujer & 0,0246 & 0,036 & 0,0431 \\
\hline & \multirow{2}{*}{2} & Hombre & 0,0014 & 0,0023 & 0,0017 \\
\hline & & Mujer & 0,0020 & 0,0024 & 0,0021 \\
\hline & \multirow{2}{*}{3} & Hombre & 0,0071 & 0,0108 & 0,0115 \\
\hline & & Mujer & 0,0119 & 0,0096 & 0,0086 \\
\hline & \multirow{2}{*}{4} & Hombre & 0,0074 & 0,0098 & 0,0075 \\
\hline & & Mujer & 0,0097 & 0,0101 & 0,0104 \\
\hline & 5 & Hombre & 0,0242 & 0,0242 & 0,0237 \\
\hline & 0 & Mujer & 0,0357 & 0,0361 & 0,0375 \\
\hline & 6 & Hombre & 0,0463 & 0,0574 & 0,0594 \\
\hline & o & Mujer & 0,0803 & 0,0705 & 0,0987 \\
\hline & 7 & Hombre & 0,0275 & 0,0293 & 0,0372 \\
\hline & 7 & Mujer & 0,0447 & 0,0503 & 0,0524 \\
\hline & 8 & Hombre & 0,028 & 0,0238 & 0,0269 \\
\hline & б & Mujer & 0,0421 & 0,0479 & 0,0423 \\
\hline & 9 & Hombre & 0,0436 & 0,0445 & 0,0496 \\
\hline & $y$ & Mujer & 0,0660 & 0,0708 & 0,0678 \\
\hline
\end{tabular}

Fuente: Elaboración propia. 